\title{
Potentially modified hydropower production under climate change in the Italian Alps.
}

\author{
Bombelli, G. M. ${ }^{1}$, Soncini, A. ${ }^{1}$, Bianchi, A. ${ }^{1}$, Bocchiola, D. ${ }^{1}$. \\ ${ }^{1}$ Dept. of Civil and Environmental Engineering DICA, Politecnico di Milano, 1. da Vinci 32, \\ 20133 Milano, Italy. daniele.bocchiola@polimi.it
}

\begin{abstract}
We present an assessment of the potential impacts of climate change on hydropower production within a paradigmatic, very highly exploited cryospheric area of upper Valtellina valley in the Italian Alps. Based on dependable and unique hydrological measures from our high altitude hydrometric network Idrostelvio during 2006-2015, we set up the Poly-Hydro model to mimic the cryospheric processes driving hydrological flow formation in this high altitude area. We then set up an optimization tool which we call Poly-Power, to maximize the revenue of the plant manager under given hydrological regimes, namely by proper operation of the hydroelectric production scheme (reservoirs, pipelines, power plants) of the area. We then pursue hydrological projections until 2100, feeding Poly-Hydro with the downscaled outputs of three general circulation models from the IPCC AR5, under the scenarios RCP 2.6, RCP 4.5, and RCP 8.5. We assess hydrological flows in two reference decades, i.e. at half century (2040-49), and end of century (2090-99). We then feed the so obtained hydrological scenarios as inputs to Poly-Power, and we project future production of hydroelectric power, with and without re-operation of the system. The average annual stream flows for hydropower production decreases along the century under all our 9 scenarios $(-21 \%$ to $+7 \%$, on average $-5 \%$ at half century, $-17 \%$ to $-2 \%$, average $-8 \%$, end of century), with ice cover melting unable to offset such decrease. Reduction in snowfall and increase in liquid rainfall are the main factors affecting the modified hydrological regime. Energy production (and revenues) at half century may increase under all scenarios $(-9 \%$ to $+15 \%,+3 \%$ on average).
\end{abstract}


At the end of century in spite of a projected increase on average $(-7 \%$ to $+6 \%,+1 \%$ on average), under the warmest scenario RCP 8.5 decrease is consistently projected ( $-4 \%$ on average). Our results provide an array of potential scenarios of modified hydropower production under future climate change, and may be used for brain storming of adaptation strategies.

Keywords: hydropower production; climate change; hydrological projections; glaciers; Italian Alps.

\section{Introduction}

Assessment of present and future water resources from the mountains arose to a growing importance in the last decade (Kaser et al., 2010; Soncini et al., 2015; 2016; 2107; Viganò et $a l ., 2015)$.

The recent intensification of climate change, highlighted in the IPCC reports (AR5, 2013; Special Report on Global Warming, 2018) suggests that the latter is likely to have a significant impact on the hydrological dynamics, especially within high-altitude areas, where the coverage of permanent glacial areas will shrink worldwide (Minora et al., 2016; Bocchiola et al., 2018a). This makes necessary the quantitative study of the dynamics of the cryosphere and of the related hydrological contributions (Bocchiola et al., 2010; Minora et $a l ., 2015)$.

In Italy, Alpine glaciers are subject lately to rapid down wasting (Smiraglia and Diolaiuti, 2015; Smiraglia et al., 2015), and largely attributed to climate changes (D'Agata et al., 2014).

It is nowadays possible to use mathematical models able to reproduce the physical processes regulating glacial dynamics (Soncini et al., 2016; 2017), including future evolution of glacial cover in response to climate change scenarios (Aili et al., 2018).

Given the large effort to monitor snow, glacial and hydrological dynamics in the high altitude areas, models are necessary to highlight the most important phenomena. Parameterization of glacio-hydrological models is cumbersome, because of the lack of accurate and continuous data (see e.g. Soncini et al., 2017), largely due to complex environmental and climatic conditions. Accordingly, often glacial-hydrological modelling and future projections, already intrinsically afflicted by large uncertainty, may become undependable. 
In turn, water from the mountains gives energy, sustains the ecosystems, provides constant supply to lakes, and irrigation in the lowlands.

Changes in the hydrological regimes of the mountains can affect management of water, particularly for water use if highly dependent on the hydrological regime, such as for hydropower production (Gaudard et al., 2013;2014; Schaefli, 2015; Ravazzani et al., 2016). Hydro-power, besides being renewable, and clean, has a relative flexibility, and the ability to indirectly store the electricity produced (i.e. as water stored) at low costs.

Such features will be even more necessary in the future, with the increasing use of intermittent renewable energy resources, such as wind and solar. Hydropower production is therefore an important monetary resource for managers and institutions in mountain regions (Hill Clarvis et al., 2014).

Here, we assess the effects of impending climate change upon the hydropower production from a large system of dedicated reservoirs in the Lombardy Region of Italy, namely the hydropower system of high Valtellina valley, in the Eastern Alps of Lombardia region in Italy. Hydrology therein is driven by cryospheric processes, including glaciers' down wasting and seasonal snow melt, and management of this complex hydropower is pursued with the main target of profit maximization, under environmental constraints (i.e. minimum instream flows, as set out by local regulation).

Given rapidly ongoing modification of the cryospheric features in this area (Soncini et al., 2017), and their expected hydrological fallout (Aili et al., 2018), one needs to assess the future (i.e. along the XXI century) hydropower potential in response to the new hydrological settings.

For doing so, we rely upon recent expertise in monitoring, and modeling of high altitude cryospheric catchments, following a well consolidated procedure to assess present and future flow regimes (see Soncini et al., 2017; Aili et al., 2018).

Based on a dependable and unique hydrological data set from a high altitude hydrometric network called Idrostelvio (Bocchiola et al., 2018b), operating since 2006, we set up our Poly-Hydro model able to mimic the cryospheric processes driving hydrological flow formation (Bocchiola et al., 2018b). Then, we set up a new, properly developed optimization tool, which we call Poly-Power, to maximize the revenue of the plant manager under given 
hydrological regimes, namely by proper operation of the hydroelectric production scheme of the high Valtellina valley.

Upon such bases, we could pursue hydrological projections until 2100, feeding Poly-Hydro with the downscaled outputs of three general circulation models from the IPCC AR5, and i) assess hydrological flows in two reference decades, i.e. at half century (2040-49), and end of century (2090-99), and ii) feed these hydrological scenarios to Poly-Power, and project future production of hydroelectric power under revenues' maximization.

The manuscript is organized as follows. In section "Case study" we escribe the main features of the basin of interest for our work. In section "Methods" we depict the methodology, and in the "Data" section we describe the data base used here. In section "Results", we display the projected evolution under climate change scenarios. In section "Discussion", we discuss how to use it in the field of hydropower production. We finally draw some conclusions and outline possible future efforts.

\section{Case Study}

The case study area covers the upper part of the Adda River basin (Alta Valtellina, High Valtellina valley, hereon HVV), closed at Le Prese, Sondalo (at $810 \mathrm{~m}$ a.s.1.), with a number of tributaries (Braulio, Frodolfo and Viola), to which one can add the Spöl river, also included in the hydroelectric system of HVV (Figure 1a). The catchment altitude ranges from $810 \mathrm{~m}$ a.s.l. to more than $3800 \mathrm{~m}$ a.s.l. of the Gran Zebrù summit, for a total area of 889 $\mathrm{km}^{2}$. There are $26 \mathrm{~km}^{2}$ of glaciers, i.e. $7.6 \%$ of the total area, the largest one being the iconic Forni glacier (ca. $11 \mathrm{~km}^{2}$ in area, e.g. Fugazza et al., 2015). A share of $75.2 \%$ of the basin dwells between 2000-3000 m a.s.l. (Figure 1b). The backbone of the HVV hydropower system, managed by A2A S.p.A. (Figure 1c), is given by two artificial reservoirs, namely San Giacomo $\left(6410^{6} \mathrm{~m}^{3}\right)$, and Cancano $\left(12410^{6} \mathrm{~m}^{3}\right)$, the latter being downstream of the former.

There are then four power stations, i.e. i) San Giacomo, upstream, at ca. $1900 \mathrm{~m}$ a.s.l., watered by San Giacomo storage, ii) Premadio, ca. $1828 \mathrm{~m}$ a.s.l., watered by Cancano impoundment, iii) Braulio, ca. $1985 \mathrm{~m}$ a.s.l., taking water from the Valfurva Valley canals (Braulio-Forni, Figure 1c). Further, a power station is cast at the outlet of the Nuovo Canale Viola, at an altitude of $1900 \mathrm{~m}$ a.s.1. approximately. 
The water collected from San Giacomo storage comes from the Valfurva and Spoel canals, and subsequently reaches the Cancano reservoir through the San Giacomo power station, built in 2004. The Cancano reservoir is then connected to the Premadio plant, with a gallery starting at $1804 \mathrm{~m}$ a.sl. The Braulio power plant instead exploits the difference in height between the Gavia-Forni-Braulio canal and the Braulio-San Giacomo canal. Similarly, the station at the outlet of the Nuovo Canale Viola exploits the vertical jump between the canal and the Cancano pool.

\section{Methods}

The methods and the models used in this work are following presented here and they are outlined in Figure 2.

\subsection{Hydrological Model}

We use here the well assessed Poly-Hydro model, a physically based, semi-distributed glaciohydrological model, already validated previously (i.e. Soncini et al., 2017; Akbari et al., 2018; Bocchiola and Soncini, 2019) with acceptable performance, and able to reproduce different components of the hydrological cycle. The model, and our approach to mimic hydrological cycle within high altitude, topographically complex catchments as here is described well elsewhere (see e.g. Aili et al., 2018), and we only provide here a broad description. Poly-Hydro tracks the water budget into soil between two consecutive days, taking as input liquid precipitation (rainfall) $R$, and ice/snow melt, $M_{I} / M_{S}$. The latter are calculated using a hybrid degree day model (see Aili et al., 2018), considering temperature $T$, and (global, topographically corrected) solar radiation $H_{G}$. Initial ice thickness $h_{i c e, \text { in }}$ on glaciers is strongly influenced by the superficial slope (i.e. the greater the slope, the thinner the ice). We estimated $h_{\text {ice, in }}$ based on force balance as described by Oerlemans (2001) by back calculation from basal shear stress $\tau_{b}[P a]$ (see e.g. Aili et al., 2018). We assessed basal shear as a function of each glacier's altitude jump $\Delta H$ as proposed by Haeberli and Hoelzle (1995). Hydrological response is modeled via Nash model (e.g. Rosso, 1984), with lag time $T_{l s, g}=n_{s, g} l_{t s, g}$, i.e. for $n$ reservoirs each with lag time $l_{t}$, for overland flow, and subsurface flow, respectively ( $s$, and $g$ subscript). 


\subsection{Hydropower model and optimization}

\subsubsection{Power production and revenues}

The Poly-Power optimization model is physically based and uses standard equations for energy production from a turbine. In general, the amount of energy production, in a given period, is evaluated starting from the power [W] generated by the turbine as

$W=\eta \cdot \gamma \cdot Q \cdot H[W]$

Where $Q$ is flow discharge, limited by a maximum value $Q_{\max }, H$ is total head including energy losses, $\eta$ is final efficiency, and $\gamma$ specific weight of water. Here we assumed that losses and efficiency can be lumped into a constant parameter $\delta$, which can be approximately taken as constant, given that flow decrease leads to decreased losses, with efficiency increase, and vice versa for flow increase. The energy $[\mathrm{KWh}]$ produced in a time lapse $\left(t_{0}-t_{i}\right)$ is an integral as

$E=\int_{t_{0}}^{t_{i}} W \cdot d t$

which discretizes in finite $\Delta t$ as

$E=\sum_{t=t_{0}}^{t_{i}} W \cdot \Delta t=\sum_{t=t_{0}}^{t_{i}} \eta \cdot \gamma \cdot Q \cdot \bar{H} \cdot \Delta t$

with $\bar{H}$ is mean head during $\Delta t$. The hydropower plant manager objective is to produce energy and sell it to the energy market with a certain price $P[€ / \mathrm{MWh}]$ (hereon we use as a general currency the Euro). A general function of the monetary gain (revenue) is given as

$f(t, Q(t))[€]=E(t, Q(t)) \cdot P(t)$,

and one wants to attain the maximum possible gain expressed in this fashion. From the instantaneous gain $f(t, Q(t))$, the total gain in a period $T$ is defined as

$F^{\prime}=\sum_{t=0}^{T} P(t) \cdot W(t) \cdot \Delta t=\sum_{t=0}^{T} P(t) \cdot \eta \cdot \gamma \cdot Q(t) \cdot \bar{H}(t) \cdot \Delta t$

i.e. our objective function to be maximized.

\subsubsection{Optimal management of hydropower plant}

We defined an optimization problem, with an initial objective function $F^{\prime}=F^{\prime}(Q)$ as 
$\max _{\mathbf{Q}} F^{\prime}(Q)=\max _{\mathbf{Q}}\left(\sum_{t=0}^{T} \eta \cdot \gamma \cdot \Delta t \cdot P(t) \cdot Q(t) \cdot \bar{H}(t)\right)$

within the range

$\left\{\begin{array}{c}Q_{\min }<Q(t)<Q_{\max } \\ V_{\min }<V(t)<V_{\max } \\ H_{\min }<H(t)<H_{\max }\end{array}\right.$

The (constraint) equations to be respected in maximization are i) continuity equation of the reservoir, ii) reservoir pool level-volume equation

$V(t)=V(t-\Delta t)+I(t) \cdot \Delta t-Q(t) \cdot \Delta t$

$H(t)=H(V(Q))=H(Q)=H(Q(t))$

with $I(t)$ natural inflow (i.e. stream flow discharge), and $V(t)$ stored water volume. To avoid unrealistic emptying of the reservoirs at end time $T$, given by undefined (i.e. potentially null) value of the stored water volume $(V(t))$ not used for production, we attached to it a monetary value using an additional factor $R_{T}$

$R_{T}=\eta \gamma \cdot \bar{P} \cdot(V(T)-V(0)) \cdot \frac{H(T)+H(0)}{2}$,

where $V(0)$, and $H(0)$ are the reservoirs' volume and head, and $\bar{P}$ the mean price during $t=0$ $T$, respectively. The final objective function is thus

$F(Q)=F^{\prime}(Q)+R_{T}=\eta \gamma \Delta t \sum_{t=0}^{T} P_{t} Q_{t} \bar{H}_{t}+\eta \gamma \bar{P}\left(V_{T}-V_{0}\right) \frac{H_{T}+H_{0}}{2}$

\section{Standard form of the optimization problem}

Poly-Power model then embeds an algorithm to solve the maximization issue as set out above. It uses Mixed Integer Quadratic Programming (MIQP, e.g. Bemporad, 2016; Takapoui et al., 2017), were an objective function is expressed in a quadratic form, defined as

$$
\max _{\bar{x}} f(\bar{x})
$$

with the objective function

$$
f(\bar{x})=g+\bar{c}^{T} \bar{x}+\frac{1}{2} \bar{x}^{T} \overline{\bar{H}} \bar{x}=g+\sum_{i=0}^{n} c_{i} x_{i}+\frac{1}{2} \sum_{k=0}^{n} \sum_{j=0}^{n} h_{k j} x_{k} x_{j},
$$

and the constraints 


$$
\left\{\begin{array} { c } 
{ \overline { x } _ { \operatorname { m i n } } < \overline { x } < \overline { x } _ { \operatorname { m a x } } } \\
{ \overline { \overline { A } } \cdot \overline { x } \leq \overline { b } } \\
{ \overline { \overline { E } } \cdot \overline { x } = \overline { d } }
\end{array} \Leftrightarrow \left\{\begin{array}{l}
x_{\min , i}<x_{i}<x_{\max , i} \\
a_{i j} x_{i} \leq b_{j} \\
e_{i} k x_{i}=d_{k}
\end{array} .\right.\right.
$$

The elements $x_{i}$ of the unknowns' vector $\bar{x}=\left[x_{1}, \ldots, x_{i}, \ldots, x_{n}\right]^{T}(1$ by $n)$ could be an integer, or a floating. The matrices of equality $\overline{\bar{A}}$, and inequality $\overline{\bar{E}}$ have size $m_{e q} \times n$, and $m_{\text {diseq }} \times 1$, respectively.

\subsubsection{Optimization problem of the hydropower system}

The unknown variables are discharge $Q_{t}$, volume $V_{t}$, and the water head $H_{t}$ for each time step $\Delta t$ during $0-T$, so that the unknowns' vector $x(1$ by $3 T)$ is

$\bar{x}=\left[Q_{1}, \ldots, Q_{T}, V_{1}, \ldots, V_{T}, H_{1}, \ldots, H_{T}\right]^{T}$.

The objective is then

$F=\sum_{t=0}^{T} \eta \gamma \Delta t \cdot P_{t} \cdot Q_{t} \cdot \frac{\left(H_{t}-H_{\{t-1\}}\right)}{2}+R_{T}$,

and the plausible range is

$$
\left\{\begin{array} { c } 
{ x _ { \operatorname { m i n } , i } = Q _ { \operatorname { m i n } } \text { if } i = 1 , \ldots T } \\
{ x _ { \operatorname { m i n } , i } = V _ { \operatorname { m i n } } \text { if } i = T + 1 , . . 2 T } \\
{ x _ { \operatorname { m i n } , i } = H _ { \operatorname { m i n } } \text { if } i = 2 T + 1 , \ldots 3 T }
\end{array} \text { and } \left\{\begin{array}{c}
x_{\max , i}=Q_{\max } \text { if } i=1, \ldots T \\
x_{\max , i}=V_{\max } \text { if } i=T+1, . .2 T \\
x_{\max , i}=H_{\max } \text { if } i=2 T+1, \ldots 3 T
\end{array}\right.\right.
$$

The constraints of the continuity equation applied to reservoirs can be described as a linear constrain in the unknowns $Q_{t}$ and $V_{t}$

$\left\{\begin{array}{c}Q_{1} \Delta t+V_{1}=V_{0}+I_{1} \Delta t \\ Q_{m} \Delta t-V_{m-1}+V_{m}=I_{m} \Delta t \text { if } m=2, \ldots, T .\end{array}\right.$

The link between head and volume is generally speaking linear, and a general function cannot be analytically defined. Instead, a piecewise function can be taken along the domain of existence, divided into $p$ sub intervals $\left[u_{l-1}, u_{l}\right]$, with $l=1, \ldots, p$

$$
H(t)=\begin{gathered}
\alpha_{1}+\beta_{1} \cdot V(t) \quad \text { if } V(t) \in\left[u_{0}, u_{1}\right] \\
\alpha_{l}+\beta_{l} \cdot V(t) \quad \text { if } V(t) \in\left[u_{l-1}, u_{l}\right], \\
\\
\vdots \\
\alpha_{p}+\beta_{p} \cdot V(t) \quad \text { if } V(t) \in\left[u_{p-1}, u_{-} p\right]
\end{gathered}
$$

to be described within the MIQP by use of equation or inequality, also with auxiliary variables, real or integer. In the present literature (e.g. Trecate et al., 2001) different methodologies are given for application of piecewise functions in optimization. A generic 
approximation can be defined for each time step $t$, such that $V_{t}$ and $H_{t}$ are connected, including auxiliary variables

$\left\{\begin{array}{l}\delta_{l, t} \text { with } l=1, \ldots, p-1, \text { integer }[0,1] \\ z_{l, t} \text { with } l=1, \ldots, p-1, \text { real variable }\end{array}\right.$.

These auxiliary variables are defined as

$$
\begin{gathered}
\delta_{1, t}=1 \stackrel{\Leftrightarrow}{\Leftrightarrow} V_{t} \geq u_{1} \\
\quad \vdots \\
\delta_{l, t}=1 \stackrel{\Leftrightarrow}{\Leftrightarrow} V_{t} \geq u_{l} \\
\vdots \\
\delta_{p-1, t}=1 \Leftrightarrow V_{t} \geq u_{p-1} \\
\text { if } \delta_{l}=1 \Rightarrow \delta_{l-1}=1 \forall t,
\end{gathered}
$$

and

$$
\begin{aligned}
z_{1, t} & = \begin{cases}\alpha_{2}+\beta_{2} \cdot V_{\mathrm{t}} & \text { if } \delta_{1, \mathrm{t}}=1 \\
\alpha_{1}+\beta_{1} \cdot V_{\mathrm{t}} \quad \text { otherwise }\end{cases} \\
z_{2, t} & =\left\{\begin{array}{cc}
\left(\alpha_{3}-\alpha_{2}\right)+\left(\beta_{3}-\beta_{2}\right) \cdot V_{t} & \text { if } \delta_{2, \mathrm{t}}=1 \\
0 \quad & \text { otherwise }
\end{array}\right. \\
z_{l, t} & =\left\{\begin{array}{cc}
\left(\alpha_{l+1}-\alpha_{l}\right)+\left(\beta_{l+1}-\beta_{l}\right) \cdot V_{t} & \text { if } \delta_{l, t}=1 \\
0 & \text { otherwise }
\end{array}\right.
\end{aligned}
$$

with leads to $H_{t}$ as

$H_{t}=\sum_{l=1}^{p-1} z_{p, t}$

The unknowns' vector $\bar{x}$ changes then to

$\bar{x}$

$=\left[Q_{1}, \ldots, Q_{T}, V_{1}, \ldots, V_{T}, H_{1}, \ldots, H_{T}, \delta_{1,1}, \ldots, \delta_{l, t}, \ldots, \delta_{p-1, T}, z_{1,1}, \ldots, z_{l, t}, \ldots, z_{p-1, T}\right]^{T}$

\subsection{Energy Price model}

To apply the previous optimization model, a model for energy dynamics is necessary, i.e. to mimic the behavior of energy demand, and electricity price, and to project their trends under climate change, specifically for the Italian electricity market. We used here the model by Bombelli et al. (submitted, 2018, see also Bombelli, 2018). In short, the model estimates energy demand, and electricity price, in response to gross domestic product GDP, temperature, and uncertainty in the form of random factors. The method was applied to the 
Italian electricity market during 2005-2013, showing an acceptable capacity of modelling the observed price fluctuations, and it is used here to provide boundary conditions as from the energy market.

\section{Data}

\subsection{Hydrological model}

The Poly-Hydro model needs input of daily temperature, and (total) precipitation. The data available here are series of mean daily temperature, and total precipitation measured at some stations, mainly from ARPA (Agenzia Regionale per la Protezione dell'Ambiente) agency of Italy, and discharge data from the project Idrostelvio. The Idrostelvio hydrometric network (11 stations) is unique high altitude flow measuring network, designed and realized within the Stelvio Lombardo Park under the umbrella of a cooperation between Consorzio del Parco Nazionale dello Stelvio, Università degli Studi di Milano UNIMI and Politecnico di Milano POLIMI. This allows to monitor water resources inside this Alpine area, of large importance hydrologically, ecologically, economically. Eight out of the 11 stations are place in undisturbed (i.e. unregulated) catchments, and we could use quite complete data sets for six of these stations, for model calibration/validation.

Ice ablation data from 15 ablation stakes during 2011-2014, kindly provided by personnel of University Milano, were used for ice melt model calibration/validation. Ice cover for 2012 as given by Lombardia region was used to initialize the Poly-Hydro module dealing with ice flow dynamics. Depending on data availability and preliminary quality check, the reference period considered for calibration/validation, covered 2006-2015 (control run CR).

We used data from 5 temperature stations, 3 rainfall stations available and 6 snow depth station (see Figure 1 and Table 1). Monthly temperature lapse rates were varied from -6.6 ${ }^{\circ} \mathrm{Ckm}^{-1}$, to $-3.6{ }^{\circ} \mathrm{C} / \mathrm{km}^{-1}$, in June (Summer) and December (Winter). Precipitation increases with altitude, with a rate from $+13 \mathrm{mmmonth}^{-1} \mathrm{~km}^{-1}$ in December (Winter) to $+32 \mathrm{mmmonth}^{-}$ ${ }^{1} \mathrm{~km}^{-1}$ in July (Summer). Input data of precipitation, and temperature were distributed on over a $100 \times 100 \mathrm{~m}$ grid and fed to the model, working at that resolution. Such grid size adopted is a reasonable trade-off between spatial accuracy (also including glaciers' dynamics simulation), and the computational time for long term simulation of climate change scenarios. 


\subsection{Hydro-power production}

Poly-Power was used to provide optimal management of the hydroelectric system. Operation of the system requires inputs as follows, i) inputs of energy price, provided at a time steps $\Delta t$, 6 hours here to reasonably account for intra-daily variation, ii) inputs of daily stream flows by Poly-Hydro, in the control run, during CR and under future GCM-RCP scenarios, also reported at $\Delta t$ resolution.

To estimate electricity price, as reported in section 3.3, we used mean daily temperatures in Italy as given by ISPRA (Higher Institute for Environmental Protection and Research of Italy, "Stato dell'Ambiente", 2014), and yearly domestic product GDP as given by OCSE, for the period of simulation.

The underlying hypothesis here is that HVV hydropower system operation can be constrained against the sole energy price, which in turn depends upon demand energy.

A teach step $\Delta t$, Poly-Power outputs estimates of i) production at each station, ii) volumes stored in each reservoir, and iii) (gross) revenues.

To provide a benchmark for future production, we used Poly-Power to build a control run CR scenario of present production, and revenues, during 2006-2015.

In lack of actual production data from A2A company, we could not validate the model. Accordingly, we could use our production estimates for the assessment of relative variation under climate change, and less for an accurate assessment of the actual production, and revenues.

\subsection{Meteo-hydrological scenarios}

To provide future (until 2100) climate, and hydrological projections, we used future projection of mean daily temperature, and precipitation in the area from CMIP5 of the IPCC (Intergovernmental Panel on Climate Change). Climate projections of temperature and precipitation are given by different GCMs, under different Representative Concentration Pathways (RCPs). The three chosen GCMs were ECHAM6 (European Centre HAmburg Model), CCSM4 (Community Climate System Model), and EC-EARTH (European Consortium Earth system model), already used before, and dependable for the area after proper statistical downscaling (e.g. Aili et al., 2018). 
The RCPs scenarios considered are named RCP2.6 (optimistic one, peak in radiative forcing at $3 \mathrm{Wm}^{-2}$ or at $490 \mathrm{ppms}$ of $\mathrm{CO}_{2}$ equivalent at year 2040, and then decline to $2.6 \mathrm{Wm}^{-2}$ ), RCP4.5 (cautious, stabilization to $4.5 \mathrm{Wm}^{-2}$, or $650 \mathrm{ppms}$ of $\mathrm{CO}_{2}$ at 2070), and RCP8.5 (pessimistic, with rising radiative forcing up to $8.5 \mathrm{Wm}^{-2}$, or $1370 \mathrm{ppms}$ of $\mathrm{CO}_{2}$ by 2100).

Temperature and precipitation values from the GCMs grids were statistically downscaled station wise using the ground based data (2006-2015), including bias, and variance correction (Groppelli et al., 2011a,b). Subsequently, we applied the correction to the GCMs projections, so obtaining for each scenario RCP, and GCM model a series of daily temperatures and total precipitation until 2100 , for a grand total of 9 scenarios.

Using the Poly-Hydro model we then generated the corresponding hydrological scenarios in terms of daily flows during 2016-2100, for the nine scenarios. The Poly-Hydro model provides estimated discharges at any point (i.e. river section) along the network. Projection of streamflows are thus produced at the inlets of each reservoir, and used to force the PolyPower model for optimal management.

We benchmark the different future scenarios against the CR for two reference decades, namely 2040-2049 (hereon, 2045, or half century), and 2090-2099 (hereon, 2045, or end of century).

\section{Results}

\subsection{Poly-Hydro Model's performance}

The Poly-Hydro model was calibrated, and subsequently validated during the period with hydrometric measurements. As reported, the model can provide estimated discharges at any point (i.e. river section) along the network. Accordingly, we could simulate streamflows at the sections corresponding to the six hydrometric stations of the Idrostelvio project reported above (Figure 1a).

Also, Poly-Hydro provides complementary variables, such as values of snow water equivalent SWE stored daily within the seasonal the snow pack, and ice melt, and ice thickness variation, both usable for qualitative assessment of the model's performance. The different calibration parameters are defined as described in Table 2, where also tuning method, and data are given. 
Albeit from some streams somewhat low scores were obtained, one has to consider that on average the results here seem acceptable, especially given large uncertainty arising in measurement, and modeling within our high altitude, topographically complex area.

\subsection{Optimal management using Poly-Power}

Figure 3 shows average monthly production of the HVV system during CR, 2006-2015. This displays maxima in December and July, typically featuring higher demand, and high price as due to heating, and cooling, respectively. In Figure 3 were also report stored volumes monthly in San Giacomo and Cancano. Stored volumes influence directly production via water availability, and piezometric head, and water stored after fulfillment of the energy demand is available for future production, say in the occurrence of dry periods. Thereby, large storage represents a measure of potential for resilience of the system. During the CR, Poly-Power mimics well the typical policy of most managers now, i.e. to keep a low pool level during late Winter, and Spring, to thenceforth store large streamflows occurring during late Spring and Summer, while satisfying demand of electricity peaking in Fall (A2A personnel, personal communication, 2018). In Figure 3 we also report a reference value of streamflows. Specifically, we calculated the total water volume entering the hydropower systems at the several intakes, shown in Figure 1c. We call this equivalent stream flow (in $10^{6}$ $\mathrm{m}^{3}, V_{e q}$, or in $\mathrm{m}^{3} \mathrm{~s}^{-1}, Q_{e q}$ ), and this represents in practice the amount of water available for withdrawal from the hydropower system HHV in a given day. The Figure 3 report the mean monthly value of $V_{e q}$ in the CR period.

\subsection{Future hydrological scenarios}

Once Poly-Hydro was tuned, we pursued our simulation exercise for our nine scenarios, during 2012-2100. We projected streamflows starting from the period 2012-2015 for continuity in the ice flow model, initialized with the last available ice cover map, available for 2012.

The future simulations of the daily meteorological data, obtained through the downscaling procedure of the several RCP and GCM, were used as inputs to the hydrological model. The 
results are then compared with those obtained during CR period, focusing upon two decades as reported (named 2045, 2095).

In Figure 4 we report projected ice volume $V_{\text {ice }}$ (2050, and 2100) against 2012 estimates. $V_{\text {ice }}$ would decrease, on average by $-60 \%(-35 \%$ to $-87 \%)$ at 2050 , with largest down wasting under CCMS4-RCP8.5. At 2100 the least reduction is -53\% for ECHAM6 RCP2.6, and the largest is $-99.88 \%$ (i.e. complete down wasting) under ECHAM6-RCP8.5.

Ice covered area ICA follows similar trend volumes, with increasing down wasting rate from RCP 2.6 to 8.5. The vertical structure of ICA displays that the reduction mainly affects the lowest altitudes, with terminus of the Forni glacier moving from 2200-2400 m a.s.1. in 2012, to 2800-3000 $\mathrm{m}$ a.s.1. under RCP 2.6, and to 3000-3200 $\mathrm{m}$ a.s.1. under RCP 8.5, at the end of the century.

The annual equivalent flow input $Q_{e q}$ in Figure 5 tends to decrease for all the simulations at 2045 , with changes from $-5.0 \%$ to $-20.6 \%$ or so. Exceptions are given under ECHAM6 RCP 4.5, ECHAM6 RCP 8.5, and EC-EARTH RCP 8.5, giving increases of $+7.3 \%,+1.7 \%$ and $+3.3 \%$, respectively. A similar situation occurs for the decade 2090-2099, with a widespread reduction, reaching $-16.9 \%$.

Average values of $Q_{e q}$ monthly in Figure 6 increase under all scenarios from October to April, with decrease in Summer, for both decades. In Winter $Q_{e q}$ increases due larger share of liquid precipitation than now, as due to increasing temperatures. July and August display the largest decrease of $Q_{e q}$, due to reduction of snow and ice melting. Figure 7 reports the monthly share of snow melt of $Q_{e q}$, present, and projected, and similarly Figure 8 displays the monthly ice melt share, the latter visibly decreasing at a fast pace until the end of the century.

\subsection{Future hydropower scenarios}

Hydrological projections were used to force the Poly-Hydro model to project future production. Poly-Power takes as input daily flow values from Poly-Hydro at water intakes. Poly-Power accounts for minimum instream flow releases MIFs as set out from Italian regulation, carries out the optimization exercise, and returns i) outputs (discharge, 
power/revenue) for the individual plants at a six hours resolution, ii) stored volumes in the reservoirs at the same resolution.

In Figure 9 we report the projected percentage variation ( $v s \mathrm{CR}$ ) of yearly average energy production ( $E$ in Eq. 3), $E_{y}$. In Figure 10 we report absolute energy production $E_{y}$ projected monthly against CR values. At half century most scenarios would provide an increase of the $E_{y}$. In particular, under RCP 2.6 one has $+1.5 \%$, under RCP $4.5+2.4 \%$, and under CPR 8.5 $+6.4 \%$. At the end of the century, RCP2.6 and RCP 4.5 projected $+3.7 \%$, and $+4.0 \%$ respectively, while the RCP8.5 scenario foresees a reduction of $-4.4 \%$.

Figure 11 display the changes in monthly reservoirs' volumes of Cancano reservoir, the largest one, twice as big as San Giacomo. This is a result of optimal management from PolyPower. The model tends to save water in Spring by increasing the storage, to then compensate for the reduction of flows in Summer. San Giacomo reservoir behave accordingly (not shown for shortness).

From the comparison of Figures 5, 9 and 10, one finds that in the future, potentially increased Spring (April-June) flows (Figure 6) lead to storage of water during that season (Figure 11), with subsequent larger than now production in both Spring (Figure 10), and Summer (JulySeptember). Instead, decreased flow availability in Summer (Figure 6) results into less storage in that season, and in Fall (Figure 11), and subsequently lower than now energy production in Fall. Increase of stream flows in late Fall (November-Dicember) as due to less snowfall under larger temperatures does not help energy production in Fall, but in facts allows storage only later for use in Winter. At the end of century under the most extreme scenario RCP 8.5 may be particularly low in November (Figure 10), and December, in response to particularly decreased storage therein (Figure 11).

\section{Discussion}

Our results highlight a number of point concerning future hydropower production within the HVV system, paradigmatic of high altitude, cryospheric driven hydropower systems in the mountain regions of Europe. 
The Poly-Hydro model was able to represent reasonably well hydrological fluxes in the six different stream gauges considered, especially given large variability in such topographically complex area. The models' parameters, reported in Table 2, were kept constant in the areas, and tuned by taking the values giving a most reasonable models' fitting considering all the six stations. These are saturated conductivity $K$, and ground flow exponent $k$ (see e.g. Groppelli et al., 2011b). Lag time $l_{t}$ for overland, and subsurface flow were tuned for each modelled catchment, and subsequently interpolated by a regular (power) function of the area (see a discussion on lag time dependence of catchment morphology e.g. in Bocchiola and Rosso, 2009), to subsequently extend lag time assessment to unmeasured sections (reported in Table 3).

Notice that a good representation of the hydrological fluxes on average in the area should be enough to mimic well water resources availability for hydropower production, independently of local noise at single stations.

In Table 3, and 4 we report the fitting scores (calibration/validation) considering the combined (sum) flows of the basins Cedec, Frodolfo and Rosole, corresponding to the catchment draining into one of the hydropower intake of the hydro system, called Forni. The yearly flow statistics and goodness of fit for such intake basin, are acceptable. Accordingly, in spite of some noise in single catchments, we obtain acceptable scores with respect to the hydropower water availability. This is important because we therefore attain an acceptable (lumped) description of water resources availability for hydropower production from the model.

As reported, we calibrated the Poly-Hydro model using the data from undisturbed subcatchments, because calibration based upon outlet data at the measured basin closure (Adda a Tirano), is bothered by large water withdrawal, and we assume that acceptable performance within such undisturbed stations would indicate on average acceptable performance at the unmeasured hydropower intake.

Also, given the presence of large reservoirs, buffering the water volumes for hydropower production, with production dynamics in practice depending upon the total input volumes (and less on the daily dynamics), a first order (i.e. on average) assessment of water availability (given by Bias), seems more important than the assessment of daily water variability (given by $R^{2}$ ). 
Use of different values of the tuning parameters for different sub-catchments may have improved slightly the results. However, such fine tuning was beyond the present scope here.

The parameters used for snow/ice melt modeling we tuned using snow/ice data as reported, which provides the best model performance, according to recent findings (e.g. Soncini et al., 2017), so such parameters should not be changed in tuning procedure, unless new data were gathered.

Hydrological fluxes would be visibly modified under our climate scenarios (Figure 6). According to our results, the hydrological regime is not largely influenced by the strong reduction of the glacial bodies (the latter shown in Figure 4). Presently ice melt reaches a summit in August nearby $2.5 \%$ or so (Figure 8 ).

Such findings are indeed in line with recent findings in the Italian Alps, where glaciers among the largest of Italy are nested, and yet glaciological contribution to hydrological fluxes is somewhat low (i.e. well below 5\% or so yearly, Soncini et al., 2017; Aili et al., 2018). In Figure 12 we report the estimated values of glacial melt share (2010-2015) of stream flows within our 5 glaciated case study catchments, plotted against the share [\%] of ice covered area ICA.

Ice melt contributions at thaw depends clearly upon Spring and Summer temperature, and the extent of ice cover area ICA. Here, in our five glaciated catchments, the yearly ice melt contribution ranges from ca. $8 \%$ for GA station (Summer, ca. 20\%) to ca. $26 \%$ at Forni glacier snout FM (Summer, 88\%) against an ICA share of $1 \%$ to $65 \%$ ca.

As a benchmark recently Soncini et al. (2017) studied the Dosdè river (ca. $17 \mathrm{~km}^{2}$, average altitude $2100 \mathrm{~m}$ a.s.1.) in Val Viola Bormina (ca. $25 \mathrm{~km}$ West of HVV area), covered by ca. $1.9 \mathrm{~km}^{2}$ of ice in Cima Piazzi group. During 2009-2014 their maximum ice melt share ranges from $75 \%$ in May to $50 \%$ in July, and the mean yearly value is $5 \%$ ca.

Aili et al. (2018) studied the Mallero river at Curlo $\left(89 \mathrm{~km}^{2}\right)$ during 1982-1992, giving on average a yearly $Q_{i c e}$ share of ca. $2 \%$ (ICA of ca. 6\%).

The largest ice melt contribution occurs therein in August and September (6\%-8\%). In Figure 11 we also report the findings of these two studies, in terms of ICA share, and ice melt share yearly, and in Summer. Clearly here we find results that are consistent with those available in the present liteature concerning glacial contribution to stream flows in this area, paradigmatic 
of the (central) Alps of Italy. In the future, we projected a reduction of ice melt contribution to ca. $1 \%$ in 2045 , and less than $0.5 \%$ in 2095 .

Rather, what will likely lead to significant changes in future hydrological regime, and hydropower production will be the modified snow cover dynamics. Presently, snow melt share of the stream flows $Q_{e q}$ reaches is $>50 \%$ during Winter and Spring (January to June), and even $>80 \%$ in March (Figure 7).

Under future climate conditions, decreased snowfall in Winter will occur as due to higher temperature (not shown for shortness, see e.g. Confortola et al., 2013 for similar results on the Serio river ca. $50 \mathrm{~km}$ South-West of HVV), and earlier melting will also occur under some scenarios (e.g. February under CCSM4 RCP8.5, and less evidently under RCP2.6, and RCP4.5), with a snow melt share higher than during CR at times, at half century. Less snow melt share will occur during Spring generally. At the end of century, snow melt share will always be lower than now in practice. Again here the obtained projections are consistent with recent investigation in the Alps (Groppelli et al., 2011b; Confortola et al., 2013; Aili et al., 2018). Eventually one could gather that the hydrological regime within the HVV area would be increasingly driven by liquid precipitation, with less and less buffering from cryospheric processes.

Hydropower production dynamics would also be modified along the century. Under the most optimist scenarios (i.e. RCP 2.6, RCP 4.5) production would be slightly increasing at half century (with the exception of CCSM4 under RCP4.5 displaying large flow decrease ass seen in Figure 5, in response to largely decreased precipitation, thus giving noticeably decreased $\left.E_{y}\right)$. At the end of century, production $E_{y}$ would further increase against CR as given by larger stream flows therein. However, under RCP8.5, future production $E_{y}$ may decrease, especially at 2095 for CCSM4, and ECHAM6, because of the noteworthy decrease of $Q_{e q}$ therein (Figure 5, CCSM4, and ECHAM6, under RCP 8.5).

Management of the reservoirs according to optimization from Poly-Power in the future, reported in Figure 11 (stored volume in Cancano reservoir, the largest one), indicates in practice that the reservoirs' volume may partly make up for decreased stream flows under some scenarios, by buffering the anticipated snow (and less importantly, ice) melt (Figures 57), to retain a sufficient water volume to sustain an equal or larger level of hydropower production as in the CR period (Figure 10) at peaking of demand in Summer (especially July, not shown), and increasing during the century in response to GDP (ever increasing, and 
affecting the base demand), and to increasing temperature (increasing demand oscillation at peaks). At the end of century, this is largely evident, as the maximum storage is attained at June, much sooner than now, i.e. in October.

In Fall however, energy production would be lower than now under all scenarios (Figure 10), as due to modified hydrology of the area, with earlier snow melting and lower Summer flows (Figure 6).

Under the RCP 8.5 scenarios at 2095 under largely decreased Summer flow (Figure 6) the Summer-Fall (September-November) storage may be much lower than now (Figure 11), and not sufficient to warrant large hydropower production in Fall demand. This season is therefore critically impacted, and as a results of less energy $E$ production there, a lower yearly target $E_{y}$ is achieved (Figure 9). In all scenarios, the volume decreases with respect to CR period specially for the RCP 8.5 scenario.

From Figure 11, one gathers that reservoirs' storage is less variable in the future than now. If one takes the average (on a decade) yearly storage variation $\Delta V_{y}=V_{\max }-V_{\min }$, with $V_{\max }$ and $V_{\min }$ maximum and minimum value of monthly storage, clearly this value is considerably larger during the $\mathrm{CR}$ period than in the future.

At present from Figure 11, for CR $\Delta V_{y}=74.210^{6} \mathrm{~m}^{3}$. At half century one has $\Delta V_{y}=57.5-74.5$ $10^{6} \mathrm{~m}^{3}, 67.210^{6} \mathrm{~m}^{3}$ on average for the nine adopted scenarios. At the end of century one has $\Delta V_{y}=48.7-69.410^{6} \mathrm{~m}^{3}, 57.410^{6} \mathrm{~m}^{3}$ on average.

Accordingly, in the future, in spite of the need for more water during Fall to fulfill maximum energy production, less water will be available, and reservoirs' storage lower than now. Similar results hold for San Giacomo reservoir (not shown). As a result, in the future reservoirs' will be oversized with respect to the available water, and optimal operation.

On the one hand, this circumstance leads to foresee a potential for a liability, arising from management of reservoirs that are too large for the regulation purposes. On the other hand, this excess of volume may be used for different purposes, namely flood dampening, ecological flow support, drought management, etc.

Among others, Gaudard et al. (2013) studied the effect of modified hydropower production in the Canton Valais of Switzerland, under reduced streamflows in response to climate change. 
They propose that adequate management may mitigate losses. They would consider constant boundary conditions of price, and demand.

Gaudard et al. (2016) further discussed potential change of revenues of hydropower energy management along the century, highlighting large uncertainty in response to change of prices. Using three emission scenarios of greenhouse gasses GHGs, A1B, A2 and RCP2.6 to force the glacio-hydrological model GERM, they optimized operation of reservoirs to maximize profit for the Canton Valais until 2100. They projected a potential increase of the revenues until $+8 \%$ at half century (2021-2050), with a decrease of $-15 \%$ to $-6 \%$ at the end of century (2071-2100). They partly attribute such decrease to large glacier down wasting under A1B, and A2 storyline. Again here our findings are consistent, especially with visibly decreasing production (until $-7 \%$ ) under RCP 8.5, comparable to storyline A1B, and especially A2 (Figure 9).

Ravazzani et al. (2016) assessed the impacts of climate change (A1B storyline of IPCC) on hydropower production of the largely regulated Toce river basin in the Italian Alps, ca. 150 $\mathrm{km}$ West of HVV here. They used simulations from two regional climate models to force Toce hydrology, and subsequently used a model of the hydropower system to define management rule under profit maximization constraints until 2050. They considered constant demand, and energy price in the future. With respect to current climate (2001-2010) they projected an increase of production in Fall, Winter, and Spring, and a reduction in June and July, giving on average an increase of $+11 \%$ to $+19 \%$ yearly (2031-2050). They found also a basically unchanged dynamics of reservoirs' storage for the regulated plants (Figure 11 in Ravazzani et al., 2016). Here by taking RCP 8.5, roughly comparable to storyline A1B until half century, we find a projected value of energy production ranging from unchanged to + $10.72 \%$, somewhat consistent with their findings (Figure 9).

Our results here seem therefore consistent with the present literature covering the link between hydrological behavior of high altitude catchments hydropower production via complex flow regulation, and potential impact of climate change.

We could exploit here the potential of Poly-Hydro model to mimic complex hydrology in this high altitude area, and subsequently use Poly-Power, a model representing the complex regulation scheme of the HVV system, paradigmatic of the complexity of many hydropower systems in the Alps, and worldwide. 
Idrostelvio project, ongoing ever since 2006 in cooperation with the Stelvio Park authority with the purpose of monitoring stream flows in this high altitude, topographically complex, and naturalistically an ecologically important area, demonstrated to of strategic importance also for the purpose of studying hydropower potential.

Accordingly, we may claim that hydrological measurements in high altitude areas can, and have to be pursued ever since, not only to monitor water resources and put forward modeling, but even to assess present, and future potential for hydropower production.

Besides hydrological measurements, first hand data of climate, snow dynamics, and glaciology are paramount necessary for stream flow estimation, and we could profit here of large historical field work in the area, and experience in hydro-glaciological modeling (e.g. Soncini et al., 2017).

Even based on such information, some noise remains here in stream flow estimates, claiming for continuous improvement of measuring and modeling strategies.

No specific information of hydropower production data was available as reported, to validate our Poly-Power outputs. However, qualitative comparison of our simulated seasonal dynamics of the Cancano and San Giacomo reservoirs (the latter not shown for shortness) against description from personnel of A2A company indicated an acceptable agreement. In this sense, our results provide an indication of the largest potential production under the expected hydrological conditions. It should be noted here that the plants' operators, despite having the same objective as set out here, normally operate without a priori knowledge of stream flows. Instead, they operate the plant using educated guess to maximize revenues, and subsequently back estimate stream flows by inverse reservoir routing (Bocchiola et al., 2010). Therefore, and whenever we could come in touch with actual production data, we could i) benchmark our CR scenario against actual production, and ii) test the attitude of the plants' manager to attain a best management strategy.

However here, rather than discussing actual hydropower production, we provided an indication of the potential for relative changes of the hydropower potential under climate change. It should be noted that use of Poly-Power allows to bypass the simplified, often unrealistic assumption of run-of-river hydropower exploitation, which provides less accurate assessment of hydropower production in complex regulation systems. 
Concerning boundary conditions to present, and future energy production, here the use of properly projected energy price conditions in response to socio-economic growth, and climate evolution allowed us to highlight scenarios of reservoir's management, and maximization until the end of the century, that are possibly more realistic than for fixed conditions of energy price, as often adopted hitherto.

Clearly our results suffer from uncertainty as given by large spreading of future projections of climate change, especially concerning precipitation inputs, as largely reported in the present literature (e.g. Faggian and Giorgi, 2009).

Concerning the choice of RCPs, in principle, all RCPs may be though as equally likely to happen in the future until the end of the century, so they all represent plausible evolutions of the climate. Therefore, by exploring different RCPs one can gather a full spectrum of potential evolution of water resources availability, and here hydropower. Different GCMs in turn provide different potential evolution of the climate under the same RCP, especially as far as precipitation is concerned. However, according to recent findings, recent climate evolution somewhat mimics more closely RCP8.5, (Fuss et al., 2014), so our results may point towards potential for decreased hydropower potential in the years to come. Exploring more climate models clearly allows exploiting of a wider array of possible future evolutions (and possibly worst case scenarios) and of adaptation therein.

Eventually, we may claim the methodology we set out here, joining experimental in situ data gathering, and explicitly data driven modeling of complex hydrological cycle in high altitude area, with physically based simulation of complex reservoirs' schemes for hydropower systems provides acceptable results in depicting hydropower production patterns in the Alps, and potential climate change impacts therein.

In the future this approach may be exploited in the future to assess optimal operation, even under climate change, and figure out and test adaptation strategies in other case study areas (e.g. for multi-purpose management, Akbari et al., 2018).

\section{Conclusions}

We here presented a study to assess potential impact of transient climate change upon hydropower production in the Alps. 
Under presently ongoing policies to reduce GHGs emission, and move to energy production based upon renewables sources, policies to enforce, and support use of hydropower are needed.

In Italy however, hydropower largely relies nowadays and historically upon a network of reservoirs dating back to 50+ years ago on average, many of which nested within the Italian Alps at high altitudes, to exploit ice and snow water resources therein (e.g. Bocchiola and Rosso, 2014).

Consolidated management strategies are mostly applied in reservoirs' operation, based upon educated guess, and operators' experience. However, such strategies may fail to hit the target of optimal revenues under future changes of the hydrological regime.

Assessment of future potential for hydropower production under modified climate, and hydrology in this area is therefore necessary, even to be able to support future efforts for enhancement of hydropower use.

Using a state of the art approach, based upon i) data driven hydrological modeling in a topographically complex area, ii) socio-economically and climatically driven assessment of energy based revenues, and iii) physically based optimal management of a complex reservoirs' system paradigmatic of Italian Alpine hydropower production, we demonstrated how future climate change may, under some scenarios, and especially at the end of the XXI century, hamper hydropower production in this area.

We found that large reservoirs in the HVV area (and possibly in similar areas) can act partially as buffers for hydrological changes, by making available water volumes usable later for production, but such effect may not cover entirely water lack.

A potential side effects of modified reservoirs' management is that the residual (excess) storage volume may be used for other purposes than hydropower conservation, say for flood dampening, droughts' management, ecological flow support, and to allow increased pumped hydropower storage (not present now in HVV system), possibly partially offsetting loss of revenues.

As always in what if studies of future conditions, large uncertainty exists, and an array of potential scenarios need be considered, including best case, and worst case conditions. 
However, exploration of a range of potential futures scenarios is a powerful tool to gather knowledge of the possible operating condition in the forthcoming, design and benchmark adaptation strategies.

The physically based, meaningful tool we provided here, also improved hereon with inclusion of further information, is properly designed to support such brain storming activity.

The method and results presented here could be therefore of large interest for stakeholders in the field of hydropower production, policy makers, and generally for those interested in optimal management of hydropower under present and future climate change.

\section{Acknowledgments.}

This work takes advantage from climate data kindly provided by ARPA (Regional Agency for the Environmental Protection) Lombardia, which the authors kindly acknowledge. Geoportale Regione Lombardia is acknowledged for providing ice cover maps for 2012. Personnel of the ESP Dept. of University Milano, namely Dr. G. Diolaiuti, and her group are kindly acknowledged for sharing information about ice cover dynamics in the area. Personnel of A2A is kindly acknowledged for discussion concerning reservoir system, and management. Idrostelvio project, funded by Parco dello Stelvio Authority supported the paper with information of hydrology and it is thereby kindly acknowledged. Personnel supporting Idrostelvio is kindly acknowledged, namely Eng. G. Confortola, Dr. U. Minora, Dr. R. Azzoni, Dr. A. Senese, Dr. D. Fugazza, Eng. E. Nana, and Mr Gianpietro Verza. The present results are in fulfilment of the activity of the Climate-Lab laboratory of Politecnico di Milano (https://www.climatelab.polimi.it/en/), which is also kindly acknowledged. Two anonymous reviewers are kindly acknowledged for providing valuable suggestions to improve the manuscript.

\section{Data availability statement}

The data that support the findings of this study are available from the corresponding author, upon reasonable request. 


\section{Reference}

Aili, T., Soncini, A., Bianchi, A., Diolaiuti, G., D’Agata, C., \& Bocchiola, D. (2018). Assessing water resources under climate change in high-altitude catchments: a methodology and an application in the Italian Alps. Theoretical and Applied Climatology, 1-22.

Azzoni, R. S., Senese, A., Zerboni, A., Maugeri, M., Smiraglia, C., \& Diolaiuti, G. A. (2016). Estimating ice albedo from fine debris cover quantified by a semi-automatic method: the case study of Forni Glacier, Italian Alps. The Cryosphere, 10, 665-679.

Akbari- Alashti, H., Soncini, A., Dinpashoh, Y., Fakheri- Fard, A., Talatahari, S., \& Bocchiola, D. (2018). Operation of two major reservoirs of Iran under IPCC scenarios during the XXI century. Hydrological Processes, 32(21), 3254-3271.

Bemporad, A. (2016). A quadratic programming algorithm based on nonnegative least squares with applications to embedded model predictive control. IEEE Transactions on Automatic Control, 61(4), 1111-1116.

Bocchiola, D., \& Rosso, R. (2009). Use of a derived distribution approach for flood prediction in poorly gauged basins: A case study in Italy. Advances in Water Resources, 32(8), 1284-1296.

Bocchiola, D. (2010). Regional estimation of Snow Water Equivalent using Kriging: a preliminary study within the Italian Alps. Geografia Fisica e Dinamica Quaternaria, 33, 314.

Bocchiola, D. (2014). Long term (1921-2011) hydrological regime of Alpine catchments in Northern Italy. Advances in water resources, 70, 51-64.

Bocchiola, D., \& Diolaiuti, G. (2010). Evidence of climate change within the Adamello Glacier of Italy. Theoretical and applied climatology, 100(3-4), 351-369.

Bocchiola, D., Mihalcea, C., Diolaiuti, G., Mosconi, B., Smiraglia, C., \& Rosso, R. (2010). Flow prediction in high altitude ungauged catchments: a case study in the Italian Alps (Pantano Basin, Adamello Group). Advances in Water Resources, 33(10), 1224-1234.

Bocchiola, D., \& Rosso, R. (2007). The distribution of daily snow water equivalent in the central Italian Alps. Advances in water resources, 30(1), 135-147.

Bocchiola, D., Senese, A., Mihalcea, C., Mosconi, B., D’Agata, C., Smiraglia, C., \& Diolaiuti, G. (2015). An ablation model for debris-covered ice: the case study of Venerocolo Glacier (Italian Alps). Geografia Fisica e Dinamica Quaternaria, 38, 113-128.

Bocchiola, D., Soncini, A., Senese, A., \& Diolaiuti, G. (2018a). Modelling hydrological components of the Rio Maipo of Chile, and their prospective evolution under climate change. Climate, 6(3), 57.

Bocchiola, D., Soncini, A., Diolaiuti, G., Smiraglia, C., Mauro, V., Franzini, C., \& Meinardi, A. (2018b) Idrostelvio: un network idrometrico per il Parco dello Stelvio Lombardo 20112015. I risultati della sperimentazione e della modellistica. [Idrostelvio, a hydrometric network for the Stelvio Lombardo Park 2011-2015. Results from measurements, and models.] $L ' A C Q U A, 4,45-58$. In Italian, Abstract in English.

Bocchiola, D., \& Rosso, R. (2014). Safety of dams against floods in Italy, Adv. Water Resour., 71, 23-31. 
Bocchiola, D., \& Soncini, A. (2019). Water resources modeling and prospective evaluation in the Indus River under present and prospective climate change. In: Khan, S., Adams, T. (Eds.): Indus River Basin: Water Security and Sustainability. Elsevier. 500 pgs. ISBN: 9780128127827.

Bombelli, G.M. (2018). L'influenza del cambiamento climatico sulla produzione idroelettrica dei grandi serbatoi lombardi [The impact of climate change on hydropower production within large reservoirs in Lombardia region]. Politecnico di Milano, MS Thesis, 853758. Academic Year 2016-2017. In Italian. Available upon request.

Bombelli, G.M., Soncini, A., Bianchi, A., \& Bocchiola, D. (2018). Influence of climate change scenarios on energy price: a case study in Italy.". Submitted, Environmental Modeling \& Assessment, September 2018.

Confortola, G., Soncini, A., \& Bocchiola, D. (2013). Climate change will affect hydrological regimes in the Alps. A case study in Italy. Journal of Alpine Research| Revue de géographie alpine, (101-3).

D’Agata, C., Bocchiola, D., Maragno, D., Smiraglia, C., \& Diolaiuti, G. A. (2014). Glacier shrinkage driven by climate change during half a century (1954-2007) in the Ortles-Cevedale group (Stelvio National Park, Lombardy, Italian Alps). Theoretical and applied climatology, 116(1-2), 169-190.

Diolaiuti, G., Bocchiola, D., D'agata, C., \& Smiraglia, C. (2012a). Evidence of climate change impact upon glaciers' recession within the Italian Alps. Theoretical and Applied Climatology, 109(3-4), 429-445.

Diolaiuti, G. A., Bocchiola, D., Vagliasindi, M., D'agata, C., \& Smiraglia, C. (2012b). The 1975-2005 glacier changes in Aosta Valley (Italy) and the relations with climate evolution. Progress in Physical Geography, 36(6), 764-785.

Diolaiuti, G., Citterio, M., Carnielli, T., D'agata, C., Kirkbride, M., \& Smiraglia, C. (2006). Rates, processes and morphology of freshwater calving at Miage Glacier (Italian Alps). Hydrological Processes: An International Journal, 20(10), 2233-2244.

Diolaiuti, G. A., Maragno, D., D'Agata, C., Smiraglia, C., \& Bocchiola, D. (2011). Glacier retreat and climate change: Documenting the last 50 years of Alpine glacier history from area and geometry changes of Dosde Piazzi glaciers (Lombardy Alps, Italy). Progress in Physical Geography, 35(2), 161-182.

Faggian, P., \& Giorgi, F. (2009). An analysis of global model projections over Italy, with particular attention to the Italian Greater Alpine Region (GAR). Climatic Change, 96, 1-2, 239-258.

Fugazza, D., Senese, A., Azzoni, R.S., Smiraglia, C., Cernuschi, M., Severi, D., Diolaiuti, G.A. (2015). High-resolution mapping of glacier surface features. The UAV survey of the Forni glacier (Stelvio National Park, Italy). Geografia Fisica e Dinamica Quaternaria, 38, 25-33.

Fuss, S., Canadell, J. G., Peters, G. P., Tavoni, M., Andrew, R. M., Ciais, P.,Yamagata, Y. (2014). Betting on negative emissions. Nature Climate Change, 4(10), 850-853.

Garavaglia, R., Marzorati, A., Confortola, G., Cola, G., Bocchiola, D., Manzata, E., Senese, A., Smiraglia, C., \& Diolaiuti, G. (2014). Evoluzione del ghiacciaio dei Forni [Evolution of Forni Glacier]. Neve e Valanghe, 81, 60-67. 
Gaudard, L., Gilli, M., \& Romerio, F. (2013). Climate change impacts on hydropower management. Water resources management, 27(15), 5143-5156.

Gaudard, L., Romerio, F., Dalla Valle, F., Gorret, R., Maran, S., Ravazzani, G., ... \& Volonterio, M. (2014). Climate change impacts on hydropower in the Swiss and Italian Alps. Science of the Total Environment, 493, 1211-1221.

Gaudard, L., Gabbi, J., Bauder, A., \& Romerio, F. (2016). Long-term uncertainty of hydropower revenue due to climate change and electricity prices. Water resources management, 30(4), 1325-1343.

Groppelli, B., Bocchiola, D., \& Rosso, R. (2011a). Spatial downscaling of precipitation from GCMs for climate change projections using random cascades: a case study in Italy. Water Resources Research, 47(3).

Groppelli, B., Soncini, A., Bocchiola, D., \& Rosso, R. (2011b). Evaluation of future hydrological cycle under climate change scenarios in a mesoscale Alpine watershed of Italy. Natural Hazards and Earth System Sciences, 11(6), 1769-1785.

Haeberli, W., \& Hölzle, M. (1995). Application of inventory data for estimating characteristics of and regional climate-change effects on mountain glaciers: a pilot study with the European Alps. Annals of glaciology, 21, 206-212.

Clarvis, M. H., Fatichi, S., Allan, A., Fuhrer, J., Stoffel, M., Romerio, F., ... \& Toreti, A. (2014). Governing and managing water resources under changing hydro-climatic contexts: The case of the upper Rhone basin. Environmental science \& policy, 43, 56-67.

IPCC (2013) Summary for Policymakers. In: Stocker TF, Qin D, Plattner G-K, Tignor M, Allen SK, Boschung J, Nauels A, Xia Y, Bex V and Midgley PM (eds) Climate Change 2013: The Physical Science Basis. Contribution of Working Group I to the Fifth Assessment Report of the Intergovernmental Panel on Climate Change. Cambridge University Press, Cambridge, United Kingdom and New York

IPCC (2018) Special Report on Global Warming of $1.5^{\circ} \mathrm{C}$ : an IPCC special report on the impacts $\mathrm{f}$ global warming of $1.5^{\circ} \mathrm{C}$ above pre-industrial levels and related global greenhouse gas emission pathways, in the context of strengthening the global response to the threat of climate change, sustainable development, and efforts to eradicate poverty.

ISPRA, Higher Institute for Environmental Protection and Research of Italy. (2014) Valori climatici normali di temperatura e precipitazione in Italia. Stato dell'Ambiente 55/2015 [Italian document].

Kaser, G., Großhauser, M., \& Marzeion, B. (2010). Contribution potential of glaciers to water availability in different climate regimes. Proceedings of the National Academy of Sciences.

Maragno, D., Diolaiuti, G.A., D’agata, C., Mihalcea, C., Bocchiola, D., Bianchi, A., Janetti, E., Riccardi, A., \& Smiraglia, C. (2009). "New evidence from Italy (Adamello Group, Lombardy) for analysing the ongoing decline of Alpine glaciers". Geografia Fisica $e$ Dinamica Quaternaria, 32, 31-39.

Minora, U., Senese, A., Bocchiola, D., Soncini, A., D’agata, C., Ambrosini, R., Mayer, C., Lambrecht, A., Vuillermoz, E., Smiraglia, C., \& Diolaiuti, G. (2015). A simple model to evaluate ice melt over the ablation area of glaciers in the Central Karakoram National Park, Pakistan. Annals of Glaciology, 56(70), 202-216. 
Minora, U., Bocchiola, D., D'Agata, C., Maragno, D., Mayer, C., Lambrecht, A., Vuillermoz, E., Senese, A., Compostella, C., Smiraglia, C., \& Diolaiuti, G. A. (2016). Glacier area stability in the Central Karakoram National Park (Pakistan) in 2001-2010: the "Karakoram Anomaly" in the spotlight. Progress in Physical Geography, 40(5), 629-660.

Mosconi, B., Diolaiuti, G.A., Maragno, D., Meraldi, E., Smiraglia, C. (2010). Strategies to reduce snow and ice ablation: investigations at the Dosdè East glacier (Lombardy Alps). Poster e Abstract, 14 ${ }^{\text {th }}$ Alpine Glaciology Meeting, Milano, 25-26 March 2010. http://users.unimi.it/glaciol/14agm/mosconi.pdf.

Pellicciotti, F., Brock, B., Strasser, U., Burlando, P., Funk, M., \& Corripio, J. (2005). An enhanced temperature-index glacier melt model including the shortwave radiation balance: development and testing for Haut Glacier d'Arolla, Switzerland. Journal of Glaciology, 51(175), 573-587.

Ragettli, S., Pellicciotti, F. Immerzeel,W.W., Miles, E.S., Petersen, L., Heynen, M., Shea, J.M., Stumm, D., Joshi S., \& Shrestha, A. (2015). Unraveling the hydrology of a Himalayan catchment through integration of high resolution in situ data and remote sensing with an advanced simulation model. Advances in Water Resources, 78, 94-111.

Ravazzani, G., Dalla Valle, F., Gaudard, L., Mendlik, T., Gobiet, A., \& Mancini, M. (2016). Assessing climate impacts on hydropower production: the case of the Toce river basin. Climate, 4(2), 16.

Rosso, R. (1984). Nash model relation to Horton order ratios. Water Resources Research, 20(7), 914-920.

Senese, A., Azzoni, R.S., Mosconi, B., Maragno, D., Smiraglia, C., \& Diolaiuti, G.A. (2013). Sperimentazione di nuovi geotessili per la riduzione della fusione glaciale: risultati dal ghiacciaio del Presena nell'estate 2012. [Use of new geo-textiles for reduction of glacial fusion: results from the Presane glacier in summer 2012]. Neve e Valanghe, 80, 60-71. In Italian with abstract in English.

Schaefli, B. (2015). Projecting hydropower production under future climates: a guide for decision- makers and modelers to interpret and design climate change impact assessments. Wiley Interdisciplinary Reviews: Water, 2(4), 271-289.

Smiraglia, C., D’Agata C., Diolaiuti G.A. (2003). I ghiacciai del bacino del Po e la loro risorsa idrica. [Po basin glaciers and water resources therein] In: Un Po di acque. DIABASIS: Reggio Emilia; 53-68. In Italian.

Smiraglia, C., Diolaiuti, G.A. (2015). Il nuovo catasto dei ghiacciai italiani. Ed. by EVK2CNR, Bergamo, Italia, 400 pp. ISBN: 9788894090802.

Smiraglia, C., Azzoni, R.S., D’Agata, C., Maragno, D., Fugazza, D., \& Diolaiuti, G. A. (2015). The evolution of the Italian glaciers from the previous data base to the New Italian Inventory. Preliminary considerations and results. Geografia Fisica e Dinamica Quaternaria, 38(1), 79-87.

Soncini A, Bocchiola D, Confortola G, Bianchi A, Rosso R, Mayer C, Lambrecht A, Palazzi E, Smiraglia C, \& Diolaiuti, G. (2015). Future hydrological regimes in the Upper Indus basin: A case study from a high-altitude glacierized catchment. Journal of Hydrometeorology, 16(1), 306-326. 
Soncini, A., Bocchiola, D., Confortola, G., Minora, U., Vuillermoz, E., Salerno, F., Viviano, G., Shrestha, D., Senese, A., Smiraglia, C., \& Diolaiuti, G. (2016). Future hydrological regimes and glacier cover in the Everest region: The case study of the upper Dudh Koshi basin. Science of the Total Environment, 565, 1084-1101.

Soncini, A., Bocchiola, D., Azzoni, R. S., \& Diolaiuti, G. (2017). A methodology for monitoring and modeling of high altitude Alpine catchments. Progress in Physical Geography, 41(4), 393-420.

Takapoui, R., Moehle, N., Boyd, S., \& Bemporad, A. (2017). A simple effective heuristic for embedded mixed-integer quadratic programming. International Journal of Control, 1-11.

Trecate, G., Letizia, P., \& Spedicato, M. (2001). Optimization with piecewise-affine cost functions. Technical Report AUT01-13, 2001, Tech. Rep.

Urbini, S., Zirizzotti, A., Baskaradas, J., Tabacco, I.E., Cafarella, L., Senese, A., Smiraglia, C., \& Diolaiuti, G. (2017). Airborne Radio Echo Sounding (RES) measures on Alpine Glaciers to evaluate ice thickness and bedrock geometry: preliminary results from pilot tests performed in the Ortles Cevedale Group (Italian Alps). Annals of Geophysics, 60(2), 0226.

Viganò, G., Confortola, G., Fornaroli, R., Canobbio, S., Mezzanotte, V., \& Bocchiola, D. (2015). Future climate change may affect habitat in Alpine streams: a case study in Italy. ASCE Journal of Hydraulic Engineering, 21(2). 
Table 1. Stations available, variables measured are temperature T, precipitation $\mathrm{P}$, snow depth S, discharge Q (available only in the period 2010-2015).

\begin{tabular}{ccccc}
\hline Station & Variable & Longitude [deg] & Latitude [deg] & $\begin{array}{c}\text { Altitude [m } \\
\text { a.s.l.] }\end{array}$ \\
\hline Bormio & T, P & 10.3720 & 46.4704 & 1950 \\
Livigno - La Vallaccia & T, P, S & 10.1549 & 46.5108 & 2655 \\
Livigno - Passo Foscagno & $\mathrm{T}$ & 10.2077 & 46.4937 & 2250 \\
Livigno - San Rocco & $\mathrm{S}$ & 10.1242 & 46.5202 & 1875 \\
Santa Caterina Plaghera & $\mathrm{S}$ & 10.4841 & 46.4034 & 2240 \\
Valdidentro - Cancano & $\mathrm{T}, \mathrm{S}$ & 10.3170 & 46.5145 & 1930 \\
Valdisotto - Oga San & $\mathrm{T}, \mathrm{P}, \mathrm{S}$ & 10.3063 & 46.4532 & 2295 \\
Colombano & $\mathrm{S}$ & 10.3318 & 46.3836 & 2114 \\
Valdisotto - Cam Boer & $\mathrm{Q}$ & 10.5848 & 46.4143 & 2495 \\
Rosole & $\mathrm{Q}$ & 10.5664 & 46.4213 & 2253 \\
Cedec & $\mathrm{Q}$ & 10.5771 & 46.4135 & 2287 \\
Frodolfo monte & $\mathrm{Q}$ & 10.5098 & 46.3774 & 2240 \\
Gavia monte & $\mathrm{Q}$ & 10.4968 & 46.3848 & 2306 \\
Alpe & $\mathrm{Q}$ & 10.4088 & 46.5251 & 2283 \\
\hline Braulio monte & & & & \\
\hline
\end{tabular}

Table 2. Model's parameter from calibration

\begin{tabular}{|c|c|c|c|c|}
\hline Parameter & Unit & Description & Calibration method & Value \\
\hline$T M F_{S}$ & {$\left[\mathrm{~mm}^{\circ} \mathrm{C}^{-1} \mathrm{~d}^{-1}\right]$} & Thermal melt factor snow & Snow depth/SWE data & 1.13 \\
\hline$R M F_{S}$ & {$\left[\mathrm{~mm}^{\circ} \mathrm{C}^{-1} \mathrm{~d}^{-1}\right]$} & Radiation melt factor snow & Snow depth/SWE data & $2.210^{-3}$ \\
\hline$T M F_{I}$ & {$\left[\mathrm{~mm}^{\circ} \mathrm{C}^{-1} \mathrm{~d}^{-1}\right]$} & Thermal melt factor clean ice & Ice melt data & 5.13 \\
\hline$R M F_{I}$ & {$\left[\mathrm{~mm}^{\circ} \mathrm{C}^{-1} \mathrm{~d}^{-1}\right]$} & Radiation melt factor clean ice & Ice melt data & $1.210^{-3}$ \\
\hline$f_{d}$ & {$\left[\mathrm{~m}^{-1} \mathrm{y}^{-1}\right]$} & $\begin{array}{c}\text { Ice flow internal deformation } \\
\text { coefficient }\end{array}$ & Aili et al. (2018) & $1.210^{-24}$ \\
\hline$f_{s}$ & {$\left[\mathrm{~m}^{-3} \mathrm{y}^{-1}\right]$} & Ice flow basal sliding coefficient & Aili et al. (2018) & $1.510^{-21}$ \\
\hline$K$ & {$\left[\mathrm{~mm} \mathrm{~d}^{-1}\right]$} & Saturated conductivity & Stream flow data & 4 \\
\hline$k$ & {$[-]$} & Ground flow exponent & Stream flow data & 1 \\
\hline$\theta_{W}$ & {$[-]$} & Water content wilting & Literature & 0.15 \\
\hline$\theta_{L}$ & {$[-]$} & Field capacity & Literature & 0.35 \\
\hline$n_{s}$ & {$[-]$} & Reservoirs overland & Literature & 3 \\
\hline$n_{g}$ & {$[-]$} & Reservoirs ground & Literature & 3 \\
\hline$l_{t s}$ & [d] & Reservoir overland ( $v s$ basin area $A_{b}$ ) & Stream flow data & $0.4 A_{b}{ }^{0.83}$ \\
\hline$L_{t g}$ & [d] & Reservoir ground ( $v s$ basin area $A_{b}$ ) & Stream flow data & $9.7 A_{b}^{0.13}$ \\
\hline$\alpha_{\text {ice }}$ & {$[-]$} & Albedo ice & $\begin{array}{l}\text { Soncini et al. (2017) and } \\
\text { Azzoni et al. (2016) }\end{array}$ & 0.30 \\
\hline$\alpha_{\text {snow }}$ & {$[-]$} & Albedo snow & $\begin{array}{l}\text { Soncini et al. (2017) and } \\
\text { Azzoni et al. (2016) }\end{array}$ & 0.70 \\
\hline
\end{tabular}


Table 3. Yearly flow statistics and goodness of fit in the period of calibration (2010-2013).

\begin{tabular}{rccccccc}
\hline \multicolumn{1}{c}{ Gauge } & $\begin{array}{c}\text { Braulio } \\
\text { Monte } \\
\text { BM }\end{array}$ & $\begin{array}{c}\text { Cedec } \\
\text { FC }\end{array}$ & $\begin{array}{c}\text { Frodolfo } \\
\text { FM }\end{array}$ & $\begin{array}{c}\text { Gavia } \\
\text { Alpe } \\
\text { GA }\end{array}$ & $\begin{array}{c}\text { Gavia } \\
\text { Monte } \\
\text { GM }\end{array}$ & $\begin{array}{c}\text { Rosole } \\
\text { FR }\end{array}$ & $\begin{array}{c}\text { Forni } \\
\text { FC+FM+FR }\end{array}$ \\
\hline$A_{b}\left[\mathrm{~km}^{2}\right]$ & 9.64 & 17.63 & 17.63 & 8.06 & .9 .12 & 7.11 & 42.37 \\
ICA $[\%]$ & - & 16.5 & 66.5 & 1.0 & 15.0 & 25.4 & 38.8 \\
$Q_{\text {obs }}\left[\mathrm{m}^{3} \mathrm{~s}^{-1}\right]$ Year & 0.535 & 1.272 & 2.057 & 0.547 & 1.632 & 0.544 & 3.491 \\
$Q_{\text {mod }}\left[\mathrm{m}^{3} \mathrm{~s}^{-1}\right]$ Year & 0.591 & 1.211 & 1.643 & 0.516 & 1.269 & 0.545 & 3.592 \\
Bias $[\%]$ Year & $10.38 \%$ & $-4.77 \%$ & $-20.11 \%$ & $-5.70 \%$ & $-22.23 \%$ & $0.19 \%$ & $2.89 \%$ \\
$R M S E\left[\mathrm{~m}^{3} \mathrm{~s}^{-1}\right]$ Month & 0.21 & 0.35 & 0.64 & 0.12 & 0.55 & 0.18 & 0.69 \\
$R^{2}[]$. & 0.52 & 0.52 & 0.45 & 0.69 & 0.24 & 0.56 & 0.11 \\
\hline
\end{tabular}

Table 4. Yearly flow statistics and goodness of fit in the period of validation (2014-2015).

\begin{tabular}{|c|c|c|c|c|c|c|c|}
\hline Gauge & $\begin{array}{c}\text { Brauli } \\
\text { o } \\
\text { Monte } \\
\text { BM }\end{array}$ & $\begin{array}{l}\text { Cedec } \\
\text { FC }\end{array}$ & $\begin{array}{c}\text { Frodolf } \\
\text { o } \\
\text { FM }\end{array}$ & $\begin{array}{c}\text { Gavia } \\
\text { Alpe } \\
\text { GA }\end{array}$ & $\begin{array}{c}\text { Gavia } \\
\text { Monte } \\
\text { GM }\end{array}$ & $\begin{array}{c}\text { Rosole } \\
\text { FR }\end{array}$ & $\begin{array}{c}\text { Forni } \\
\text { FC+FM+F } \\
\mathbf{R}\end{array}$ \\
\hline$A_{b}\left[\mathrm{~km}^{2}\right]$ & 9.64 & 17.63 & 17.63 & 8.06 & 19.12 & 7.11 & 42.37 \\
\hline $\mathrm{ICA}[\%]$ & - & 16.5 & 66.5 & 1.0 & 15.0 & 25.4 & 38.8 \\
\hline$Q_{o b s}\left[\mathrm{~m}^{3} \mathrm{~s}^{-1}\right]$ Year & 0.403 & 1.36 & 1.545 & 0.420 & 1.61 & 0.707 & 3.228 \\
\hline$Q_{\text {mod }}\left[\mathrm{m}^{3} \mathrm{~s}^{-1}\right]$ Year & 0.493 & 1.083 & 1.908 & 0.406 & 1.104 & 0.541 & 3.587 \\
\hline Bias [\%] Year & $22.24 \%$ & $\begin{array}{c}- \\
20.38 \%\end{array}$ & $23.50 \%$ & - & $\begin{array}{c}- \\
31.45 \%\end{array}$ & $\begin{array}{c}- \\
23.51 \%\end{array}$ & $11.12 \%$ \\
\hline$R M S E\left[\mathrm{~m}^{3} \mathrm{~s}^{-1}\right]$ & & & & & & & 0.66 \\
\hline Month & 0.32 & 0.59 & 0.42 & 0.10 & 0.56 & 0.23 & \\
\hline$R^{2}[]$. & 0.21 & 0.06 & 0.19 & 0.63 & 0.41 & 0.23 & 0.51 \\
\hline
\end{tabular}



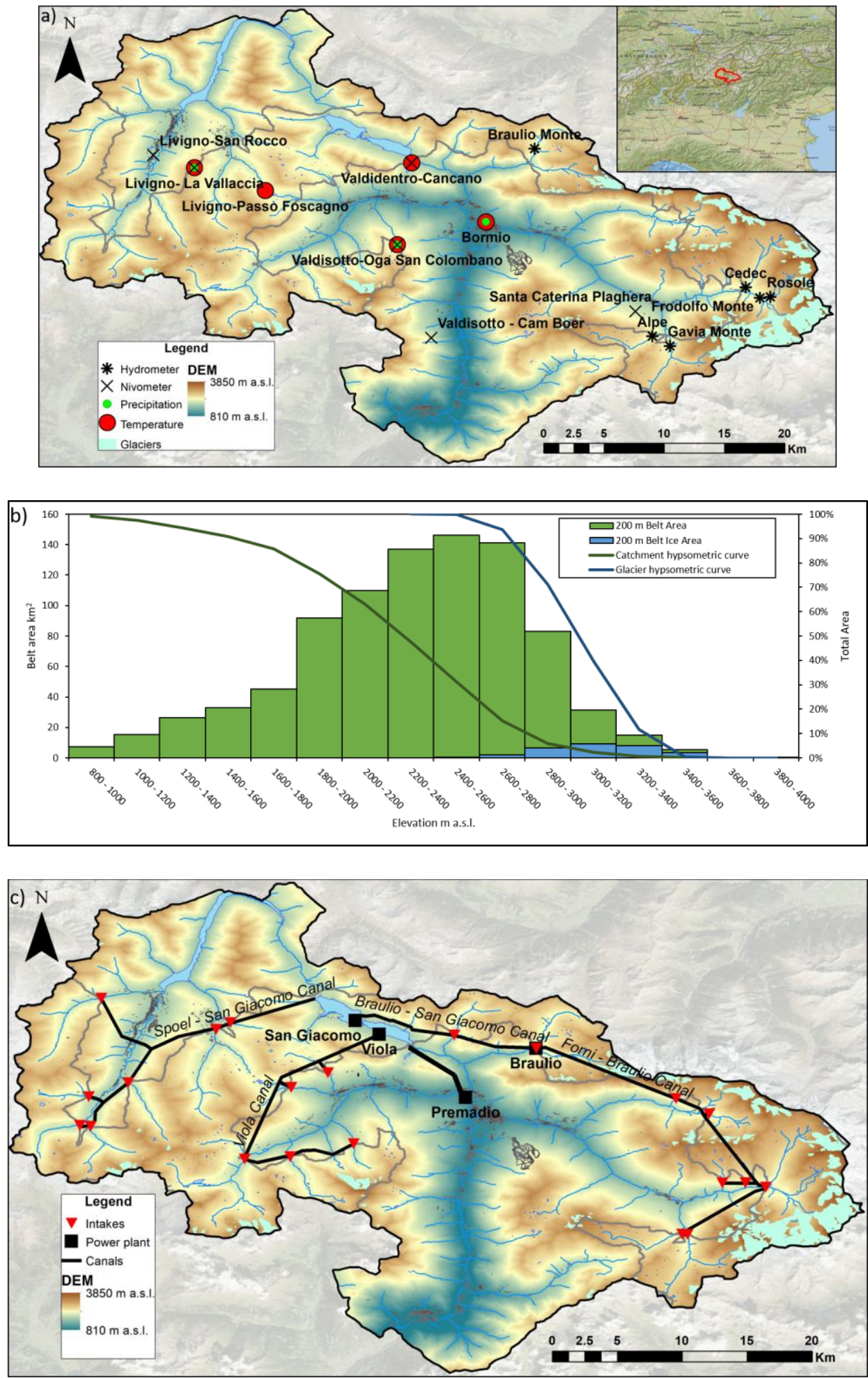

Figure 1. Case study area (Alta Valtellina). a) Location of gauging/weather stations and glaciers. b) Hypsometry curve of basin. c) Hydropower plant schemes. 


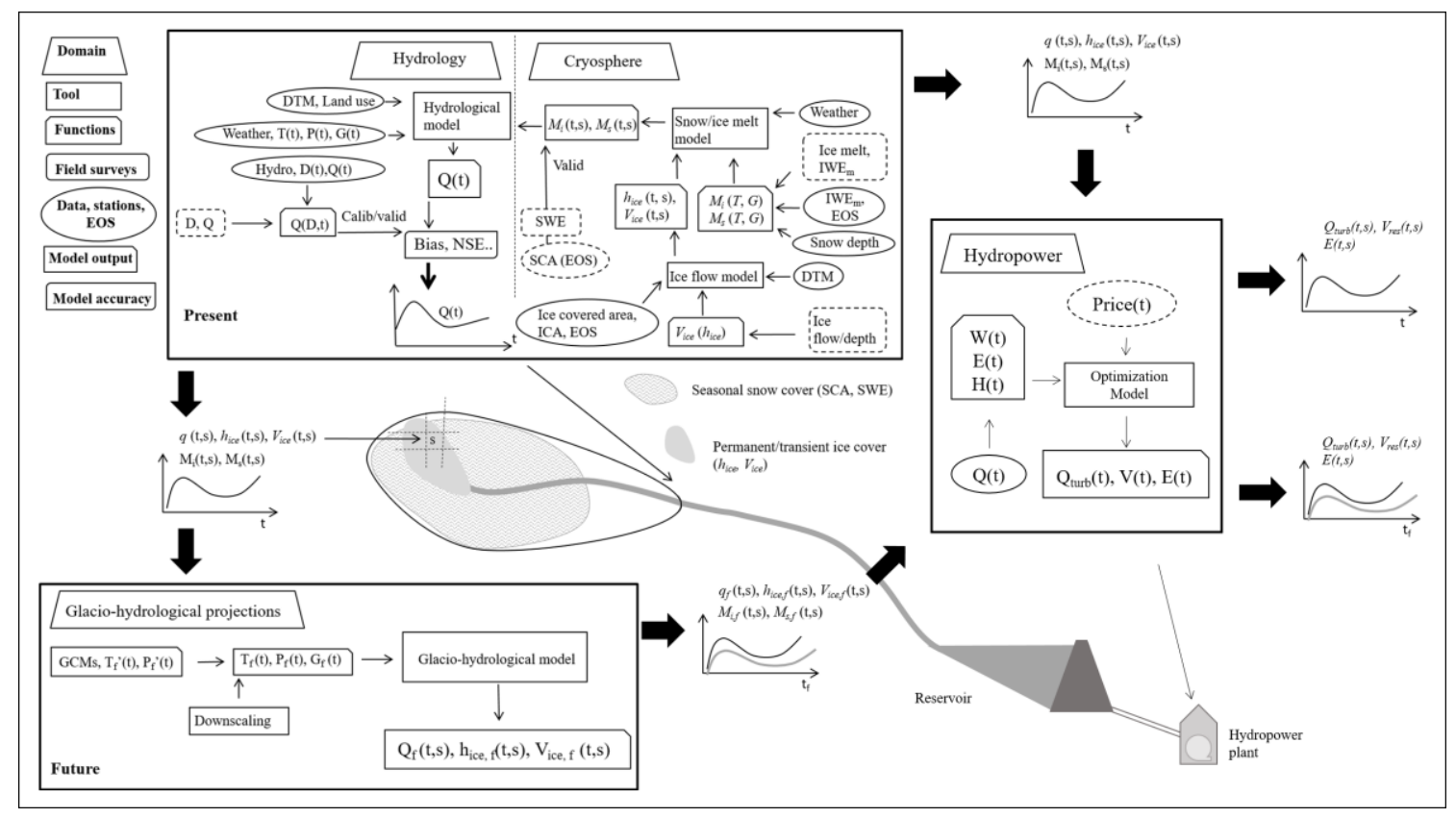

Figure 2. Proposed methodology for hydrological and hydropower modeling of the high altitude catchment, and projections under climate change. In the flow chart the necessary tools are reported, as per 7 categories, i.e. domain (e.g. hydrology, cryosphere), tools (e.g. hydrological model, snow melt model), functions (e.g. snow melt Ms as a function of temperature, and radiation Ms (T, G), etc..), necessary data from field surveys or other sources (ice melt from stakes, ice volume loss from topographic methods, earth observation from space EOS, etc..) data (weather, snow depth, SCA from remote sensing, etc..), model outputs (e.g. ice melt in time and space Mi $(\mathrm{t}, \mathrm{s})$ ), and model accuracy (e.g. Bias, NSE). T(t) is daily temperature, $P(t)$ daily precipitation, $G(t)$ is solar radiation, $D(t)$ daily flow depth at hydro station, $\mathrm{Q}(\mathrm{t})$ is daily discharge at outlet section. $\mathrm{Mi}(\mathrm{t}, \mathrm{s})$ is daily ice melt in a given place (cell) s, Ms $(t, s)$ is daily snow melt, $\mathrm{q}(\mathrm{t}, \mathrm{s})$ is daily runoff in cell $\mathrm{s}$, hice $(\mathrm{t}, \mathrm{s})$ is daily ice depth, and Vice $(t, s)$ daily ice flow velocity. SCA is snow covered area. SWE is snow water equivalent. ICA is ice covered area, IWEm is water equivalent of ice melt. Bias is systematic error on average, NSE is Nash-Sutcliffe Efficiency. Tf' $(\mathrm{t}), \mathrm{Pf}^{\prime}(\mathrm{t})$ are (future/projected) temperature and precipitation from GCMs before downscaling (biased); $\mathrm{Tf}(\mathrm{t}), \operatorname{Pf}(\mathrm{t})$ future daily temperature and precipitation after downscaling (unbiased). Dashed lines indicate methods/data that could be used generally as alternatives, but were not used here. $Q(t)$ is (present/future) inflow at reservoirs, $\mathrm{W}(\mathrm{t})$ is generated power from turbines, $\mathrm{E}(\mathrm{t})$ is total energy from the hydropower plant, $H(t)$ is turbine head. Price $(t)$ is gross energy price. $Q_{\text {turb }}(t)$ is turbine flow, $\mathrm{V}(\mathrm{t})$ is reservoir volume. Adapted from: Aili et al. (2018). 


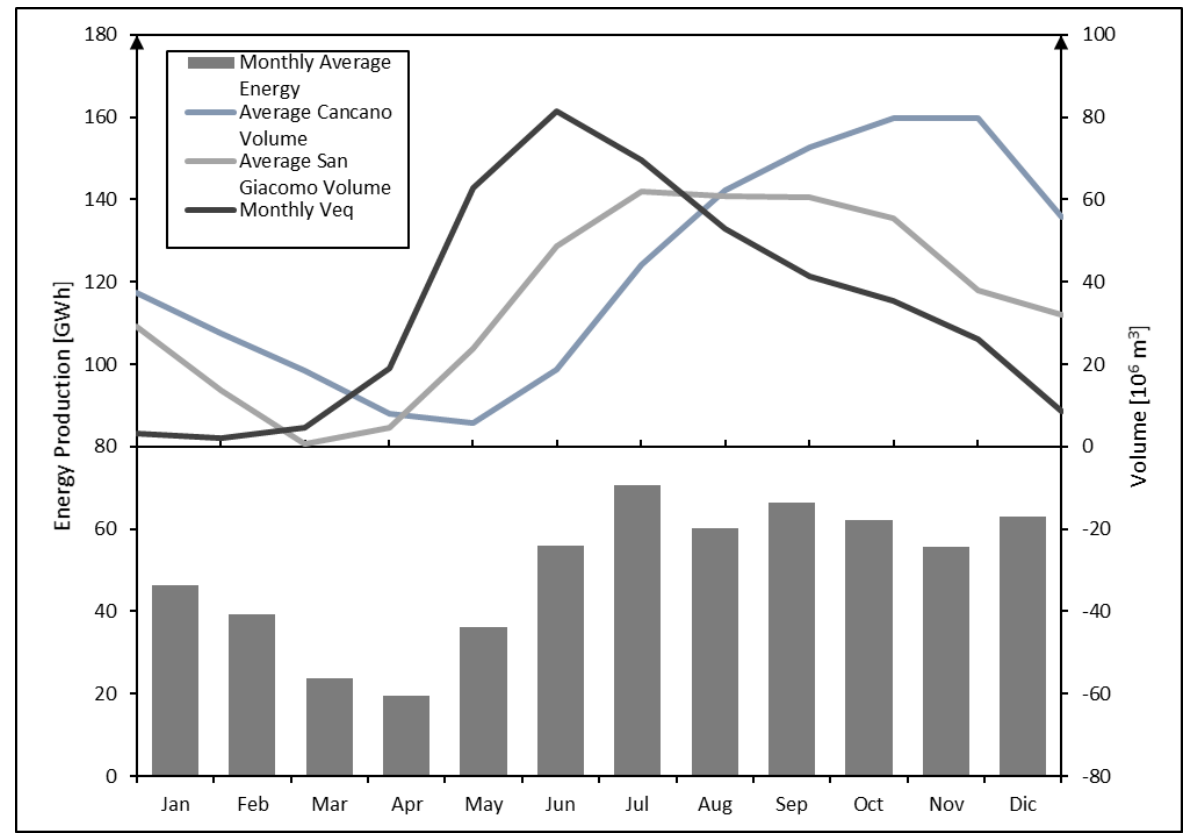

Figure 3. Monthly Average Energy Production and Volume trends for the reference period 2006-2015. Left y axis, Energy Production [GWh]. Right y axis, Volume $\left[10^{6} \mathrm{~m}^{3}\right]$, and simulated equivalent streamflow in input to the hydropower system. 


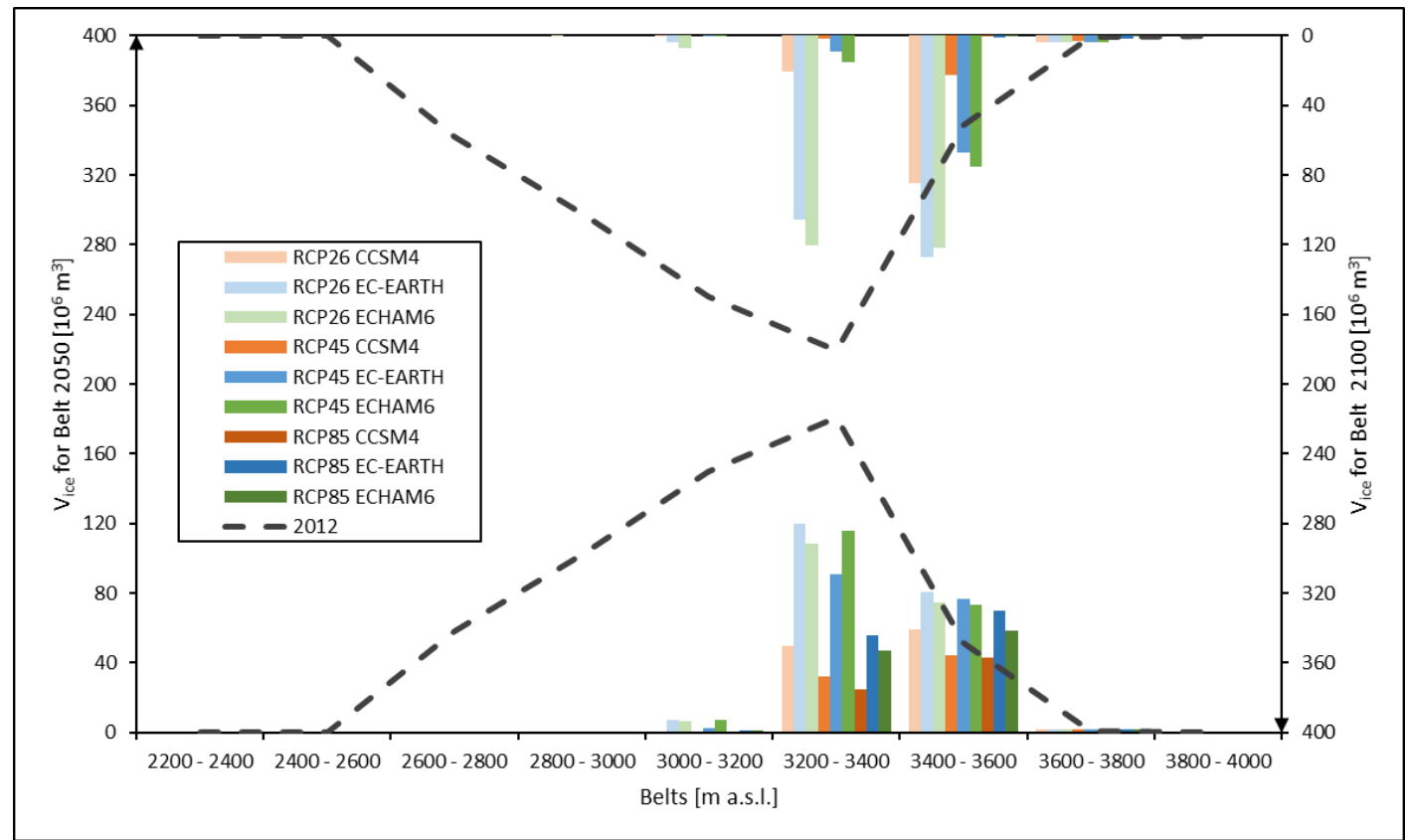

Figure 4. Projected ice volume for belts against reference period (2012). Left y axis, 2050. Right $y$ axis, values upside down, 2100. 


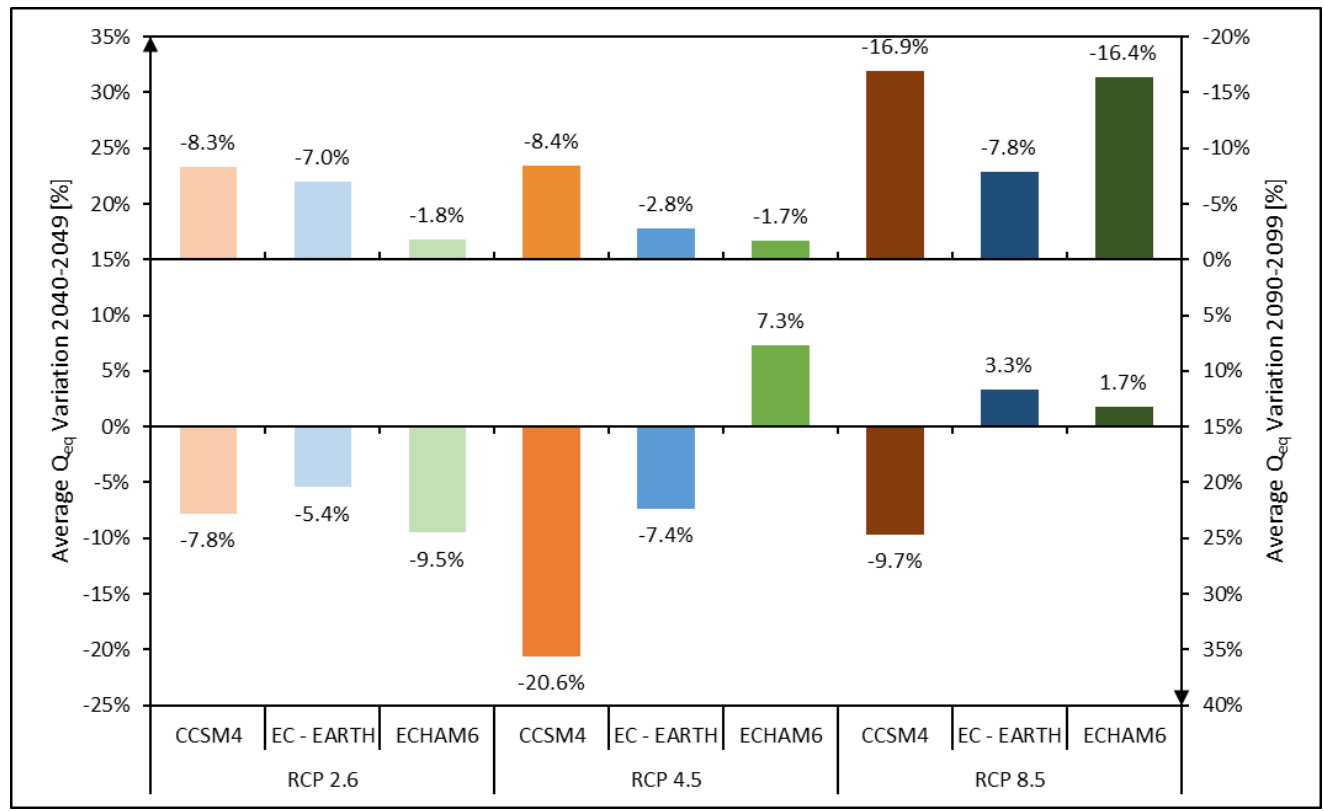

Figure 5. Variation of yearly average flow for each combination of GCM and RCP vs. the control run period (2006-2015). Left $y$ axis, 2040-2049. Right $y$ axis, values upside down, 2090-2099. 


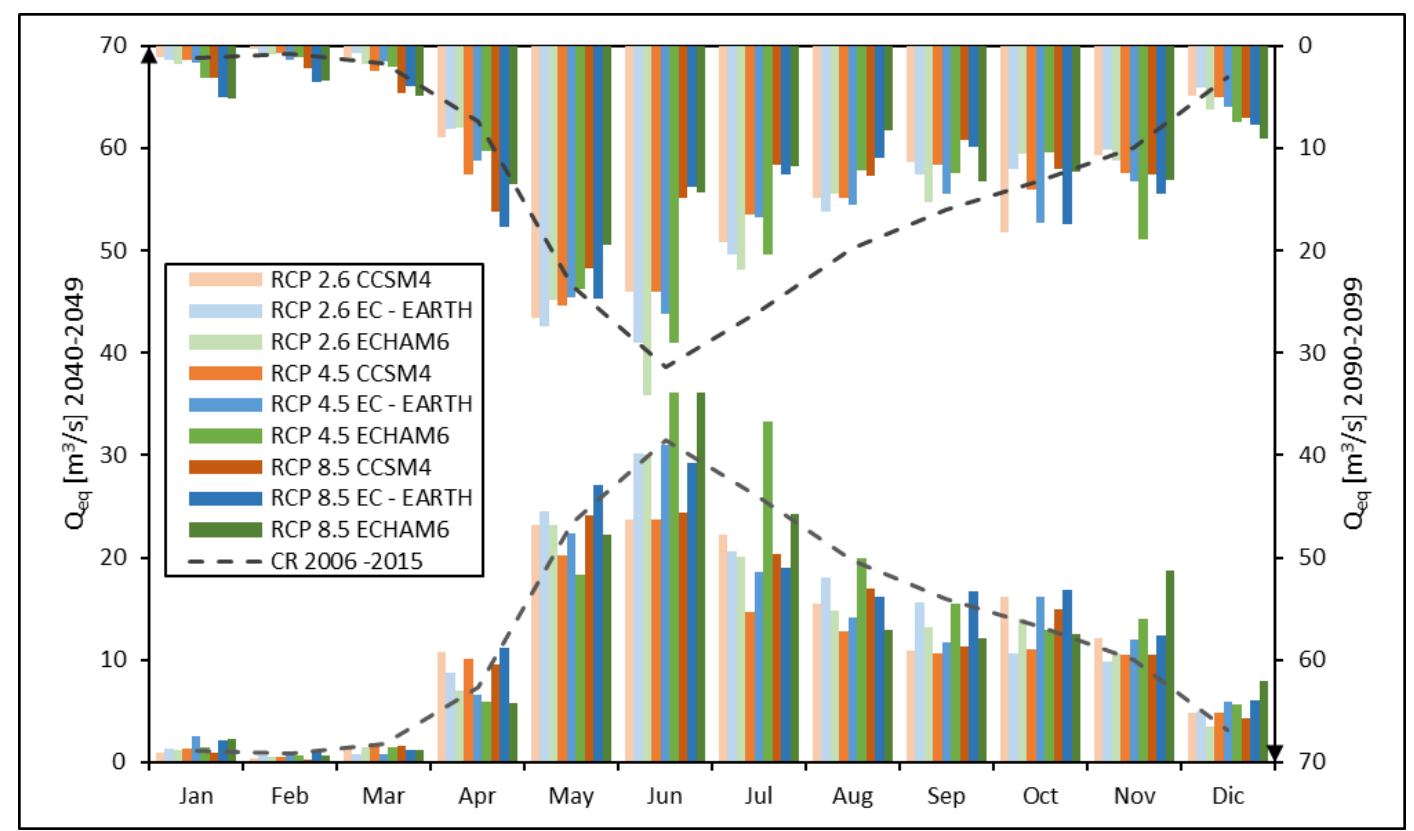

Figure 6. Monthly flow for each combination of GCM and RCP vs. the control run period (2006-2015). Left y axis, 2040-2049. Right y axis, values upside down, 2090-2099. 


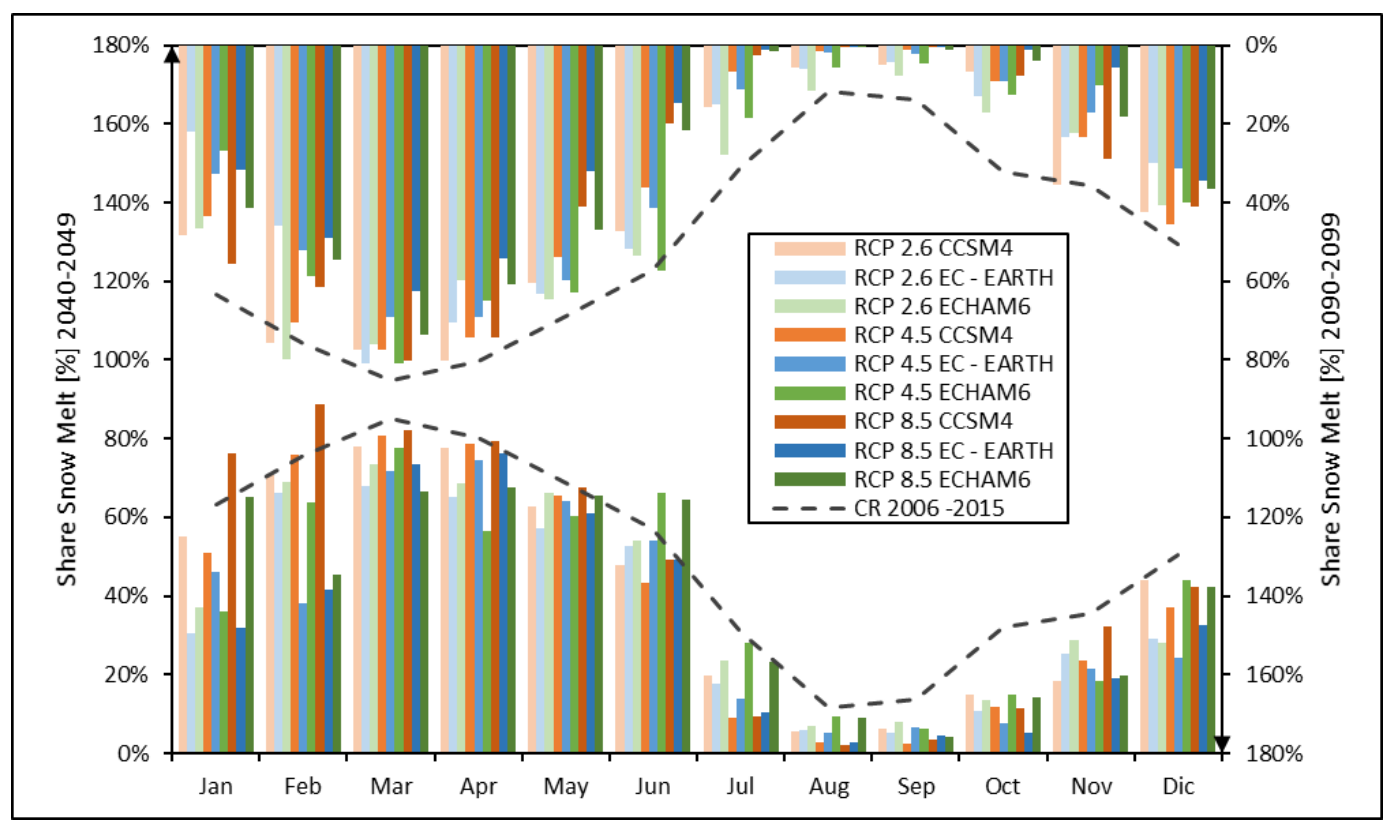

Figure 7. Monthly snow melt component of discharge for each combination of GCM and RCP vs. the control run period (2006-2015). Left y axis, 2040-2049. Right y axis, values upside down, 2090-2099. 


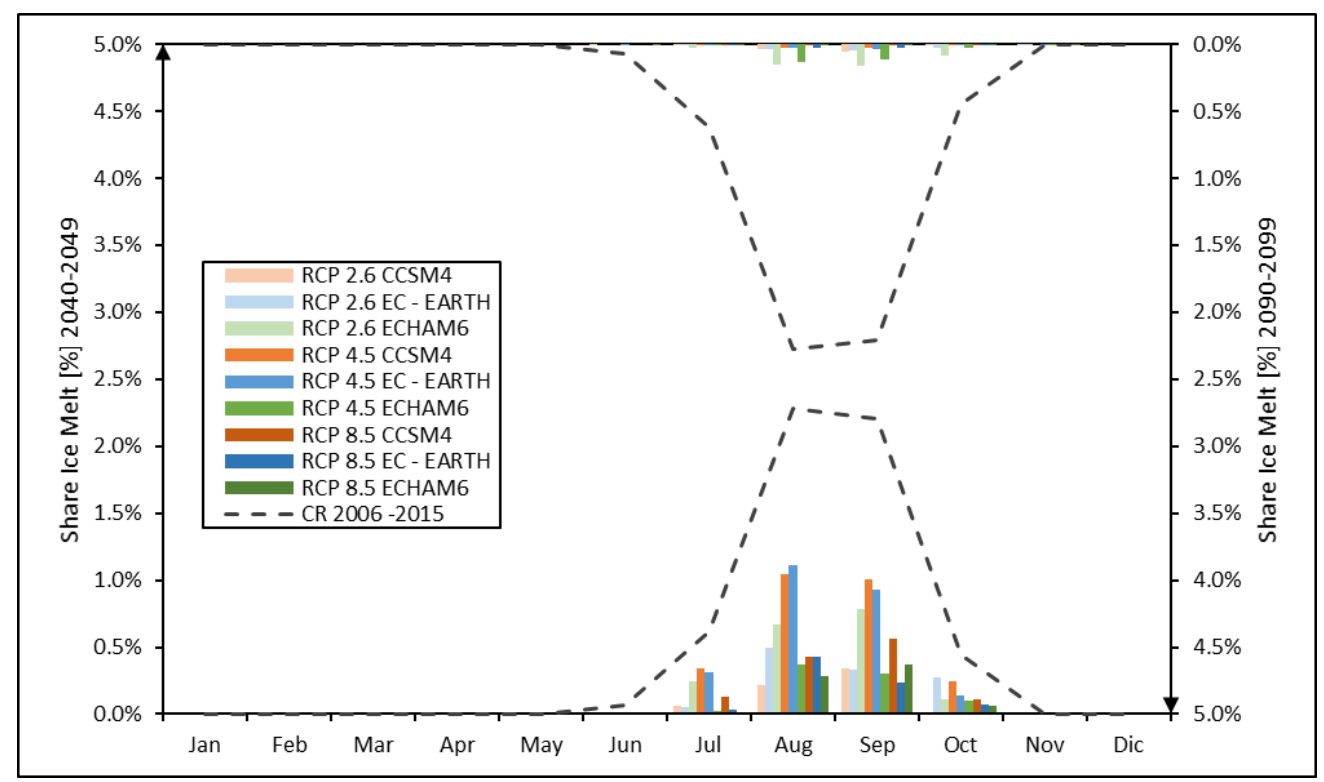

Figure 8. Monthly ice melt component of discharge for each combination of GCM and RCP vs. the control run period (2006-2015). Left y axis, 2040-2049. Right y axis, values upside down, 2090-2099. 


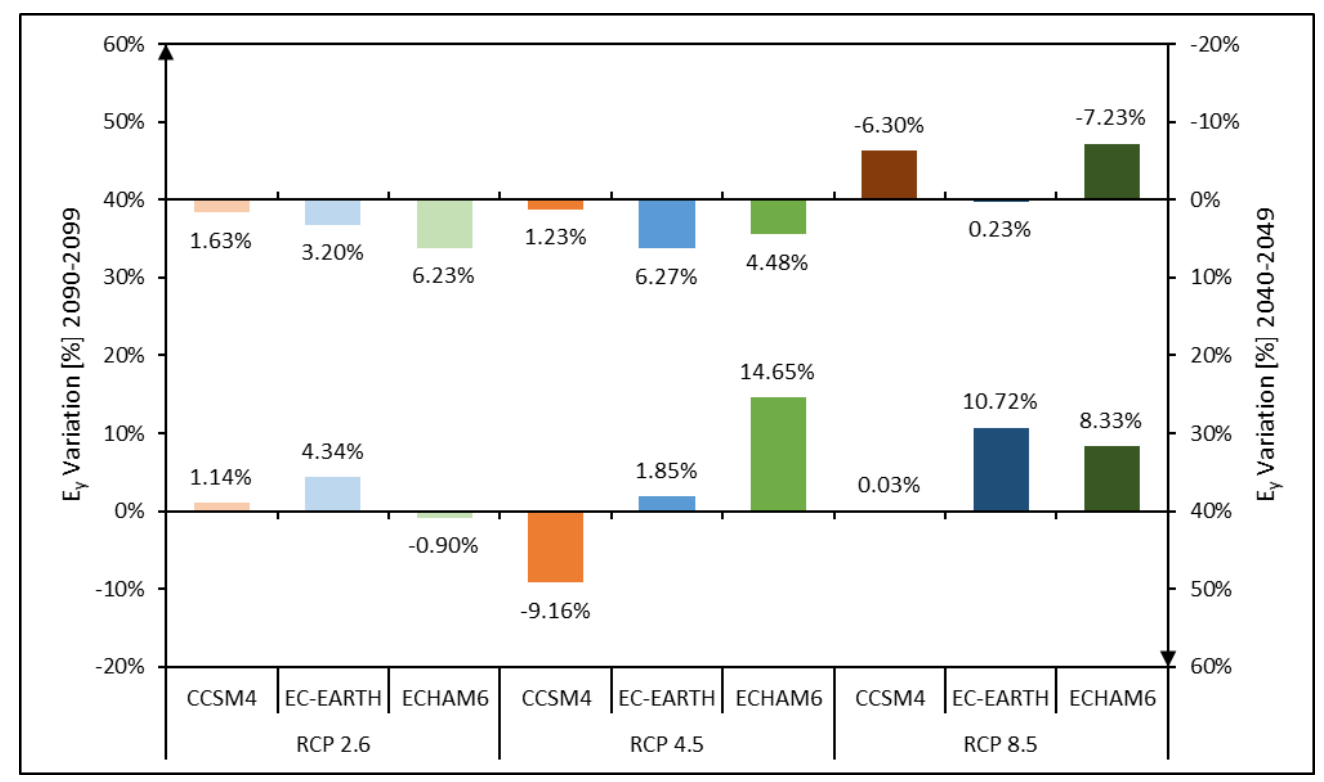

Figure 9. Variation of yearly average energy production of the hydropower plants for each combination of GCM and RCP vs. the control run period (2006-2015). Left y axis, 20402049. Right y axis, values upside down, 2090-2099. 


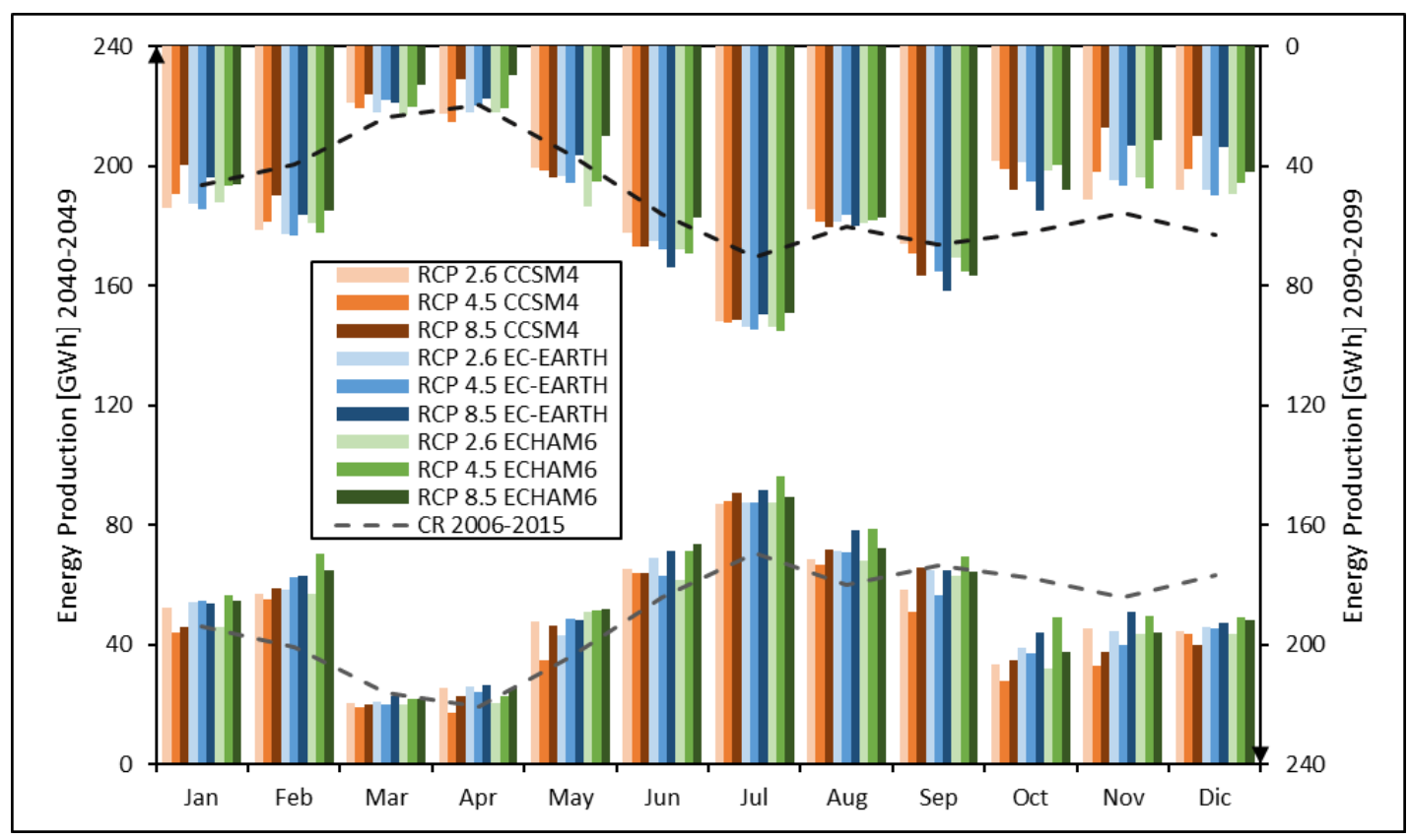

Figure 10. Monthly trend of energy production $E$ for each combination of GCM and RCP $v s$ the control run period (2006-2015). Left y axis, 2040-2049. Right y axis, values upside down, 2090-2099. 


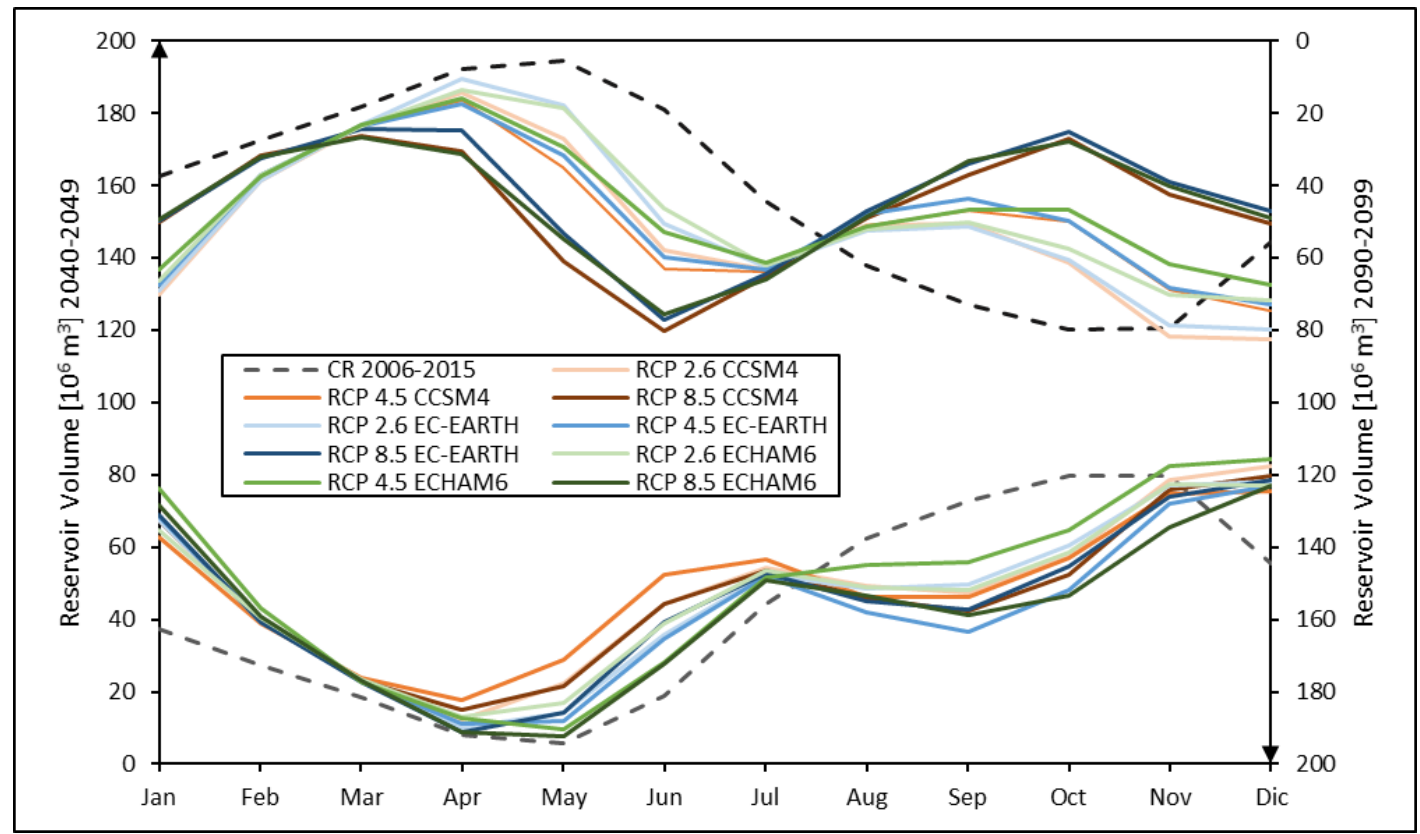

Figure 11. Monthly trend of reservoir volume for each combination of GCM and RCP $v s$ the control run period (2006-2015). Left y axis, 2040-2049. Right y axis, values upside down, 2090-2099. 


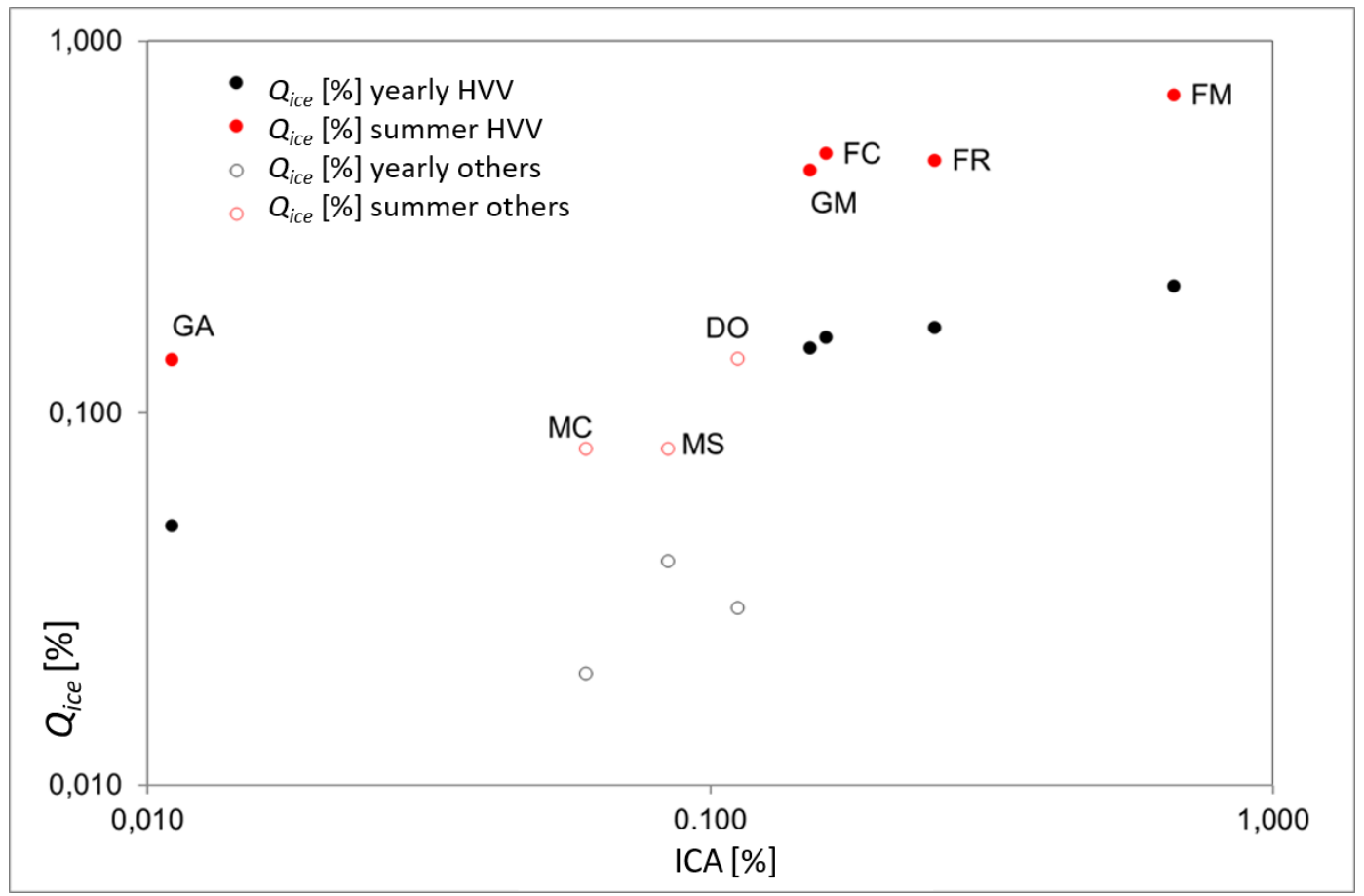

Figure 12. Share of present stream flows as from glacial melt $Q_{i c e}$, yearly, and during summer for glacier fed catchments in the HVV system. As a benchmark we report the calculated values in other catchments nearby in Valtellina valley. MC is Mallero in Curlo, MS is Mallero in Sondrio (see Aili et al., 2018), DO is Dosdé catchment (Soncini et al., 2017). Bilogarithmic scale used for readability. 


\section{Graphical Abstract}

1) We assess impacts of climate change on future hydropower production in a large plant in the Italian Alps, using Poly-Hydro model, fed with outputs from general circulation models from the IPCC AR5.

2) Annual stream flows would decrease along the XXI century with faster ice melting unable to offset the trend.

3) Energy production may increase on average, with however consistently projected decrease along under the warmest scenarios of RCP 8.5.

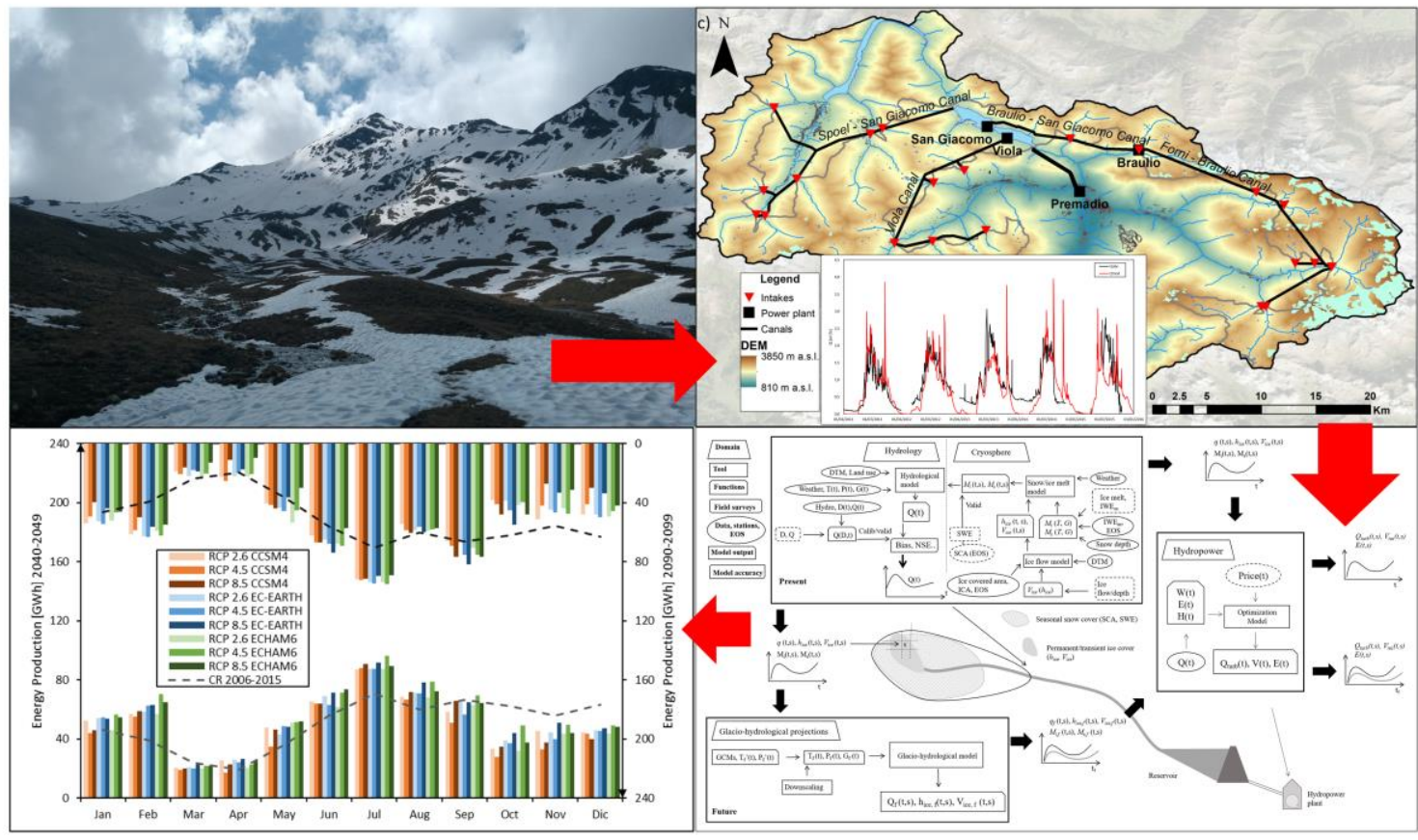

